المجلة الدولية للدراسات التربوية والنفسية

بحث رقم

المجلد التاسع، العدد الثالث، 810:791

حزيران (2021)

\title{
فاعلية بيئة تعليمية إلكترونية في تنمية مهارات الإنـاءات الهندسية في الرياضيات لدى طالبات الصف العاشْر
}

محمد فؤاد أبو عودة'، مجدي سعيد عقل² خديجة محمد بدوى3 1أستاذ المناهج وطرق تدريس العلوم المساعد- قسم المناهج وطرق التدريس-كلية التربية

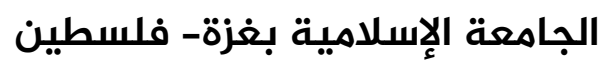

2 2 الجامعة الإسلامية بغزة- فلسطين

باحثة- قسم المناهج وطرق التدريس- كلية التربية- الجامعة الإسلامية بغزة- فلسطين فلامن

' ${ }^{1}$ odaa@iugaza.edu.ps, ${ }^{2}$ msaqel@iugaza.edu.ps, ${ }^{3}$ Eng.khbedwan1@gmail.com

قبول البحث: 2021/1/1

مراجعة البحث: 2020/11/28

استلام البحث: 2020/11/7

DOI: https://doi.org/10.31559/EPS2021.9.3.5

(2) This file is licensed under a Creative Commons Attribution 4.0 International 


\section{فاعلية بيئة تعليمية إلكترونية في تنمية مهارات الإنشاءات الهندسية في الرياضيات لدى طالبات الصفف العاشر}

محمد فؤاد أبو عودة'، مجدي سعيد عقل2، خديجة محمدل بدوى33

1 أستاذ المناهج وطرق تدريس العلوم المسـاعد-قسم المناهج وطرق التدريس-كلية التربية الجامعة الإسلامية بغزة- فلسطين

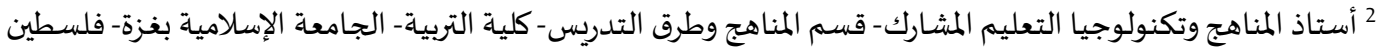

3 باحثة- قسم المناهج وطرق التدريس- كلية التربية- الجامعة الإسلامية بغزة- فلسطين

1 modaa@iugaza.edu.ps, 2 msaqel@iugaza.edu.ps, 3 Eng.khbedwan1@gmail.com

DOI: https://doi.org/10.31559/EPS2021.9.3.5 2020/11/7 مراجعة البحث: 2020/11/28 قبول البحث: 2021/1/1 البحث

هدف البحث للكشف عن فاعلية بيئة تعليمية إلكترونية في تنمية مهارات الإنشاءات الهندسية في الرياضيات لدى طالبات الصف العاشر في فلسطين، واتبع البحث المنهج شبه التجريبي بتصميم المجموعة التجريبية الواحدة ذات القياس (قبلي- بعدي)، حيث قام الباحثون ببناء أدوات الدراسة والمتمثلة في اختبار معرفي، وبطاقة تقييم لقياس مهارات الإنشاءات الهندسية، والتي تم تطبيقهما على عينة قوامها (22) طالبة من طالبات الصف العاشر، من مدرسة علي بن أبي طالب الثانوية للبنات. وقد خلص البحث إلى فاعلية البيئة التعليمية الإلكترونية في تنمية مهارات الإنشاءات الهندسية، حيث بلغ معدل الكسب بلاك (1.37)، كذلك وجود فروق ذات دلالة إلهات إحصائية عند مستوى دلالة (م=0.05) بين متوسطي درجات طالبات الصف العاشر في الاختبار المعرفي لمهارات الإنشاءات الهندسية قبل وبعد التطبيق لصالح التطبيق البعدي، كذلك وجود فروق ذات دلالة إحصائية عند مستوى دلالة (م=0.05) بين متوسطي درجات طالبات الصف العاشر في بطاقة التقييم لمهارات الإنشاءات الهندسية قبل وبعد التطبيق لصالح التطبيق البعدي. وقد أوصى البحث بتوظيف بيئات التعلم إلكترونية في تعليم الإنشاءات الهندسية، والعمل على عقد دورات تدريبية في التعليم الإلكتروني للمعلمين. الكلمات المفتاحية: بيئة تعليمية إلكترونية؛ مهارات الإنشاءات الهندسية؛ الرياضيات.

تعدّ الوسائل التكنولوجية جزءاً من الحياة اليومية للطلبة داخل وخارج الفصل الدراسي، وعلى الرغم من أن تقنيات أخرى مثل السبورة والقلم

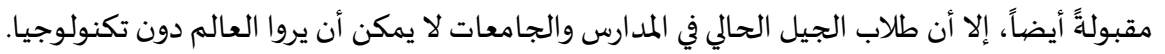
ومع التقدّم التكنولوجي في مجال التعليم، أصبح التّعلم الإلكتروني جزءً من مشهدٍ جديد، يوفر التعلم التلقائي، من خلال استخدام أجهزة الحاسوب من قبل الطلاب من جميع الأعمار والخلفيات، حيث تمكنهم من التفاعل والتعاون والتعلم.

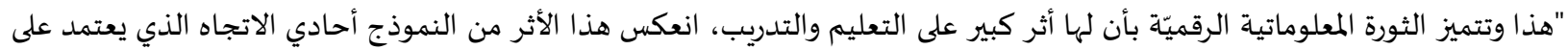

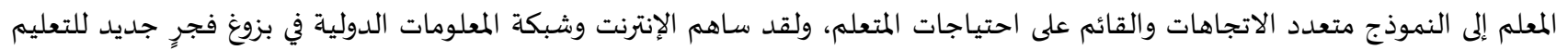

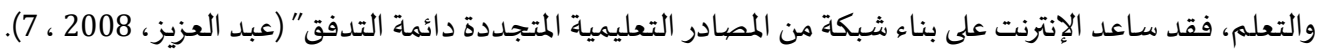
لذلك فإنه من الأهمية بمكان تطبيق المبادئ التقنية في تسهيل عملية التعليم والتعلم، حيث تزيد هذه التقنية من فرص الوصول للمعلومات من قبل المعلم المحترف، كما تعزز مفاهيم التعليم وتجعل عملية التعليم والتعلم أكثر بساطة. 
وقد ظهرت بعض التقنيات الحديثة في مجال التعلم الإلكتروني التي أسهمت في إيصال الكثير من المعلومات والمهارات بكفاءة عالية، حيث تشير

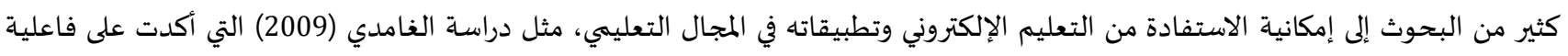

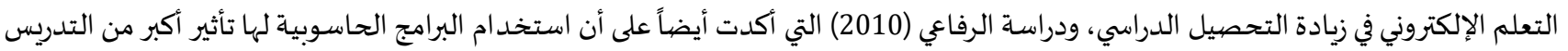
بالطريقة العادية على تحصيل الطلاب.

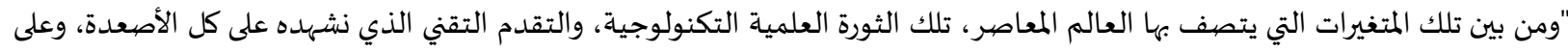

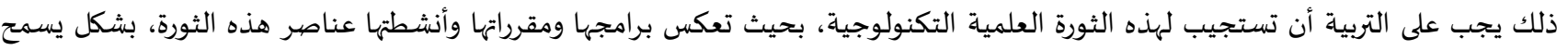
للأجيال المعاصرة بالتكيف مع طبيعة العصر الذي يعيشونه، وأن يستفيد التعليم من تقنيات تلك الثورة التكنولوجية الثياة في تفعيل أنشطته وتسهيل

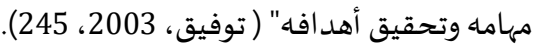
ويشير عبد الحميد (2005، 47)إلى أن "التعليم الإلكتروني قد ساهم في تجاوز العديد من المشكلات الخاصة بتقديم الخدمات التحات التعليمية في

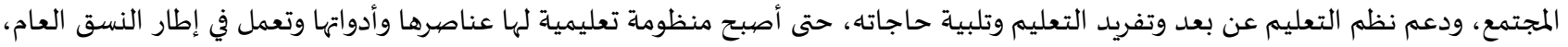

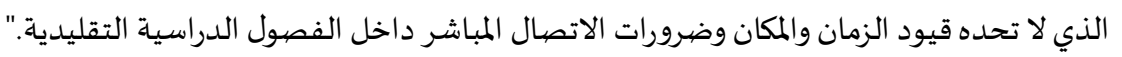
وقد عرف هورتن وهورتن (Horton and Horton, 2003) المفهوم الشامل للتعلم الإلكتروني بأنه أي استخدام لتقنية الويب والانتانترنت لإحداثداث التعلم. وعرفه هندرسن (Henderson, 2002) بأنه التعلم عن بعد باستخدام تقنية الحاسب. ويعرفه بسيوني (2007، 217) بأنه "شكل من أشكال التعلم عن بعد كطريقة للتعليم باستخدام آليات الاتصال الحديثة كالحاسب والشبكات

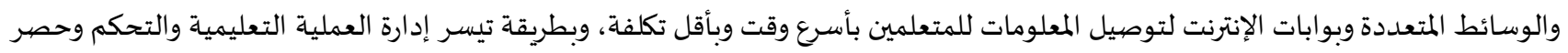

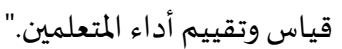

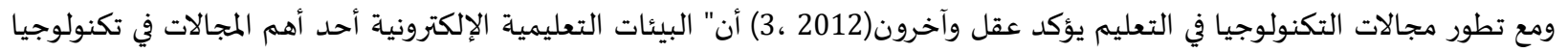

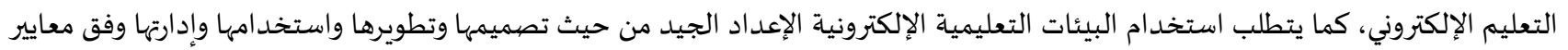

محددة من أجل ضمان فاعلية توظيفاه في العملية التعليمية."

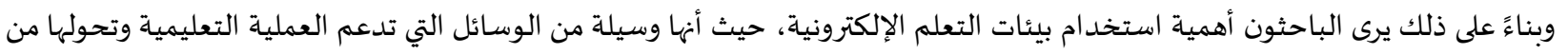

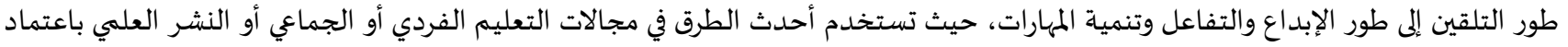

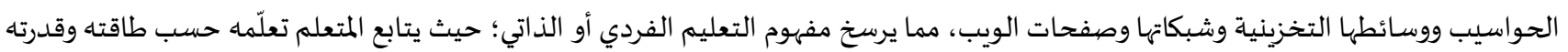

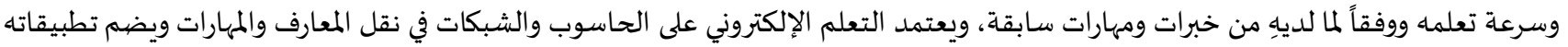

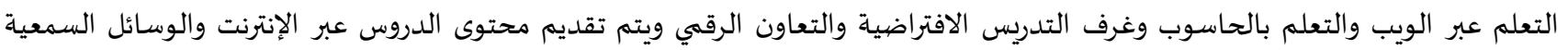

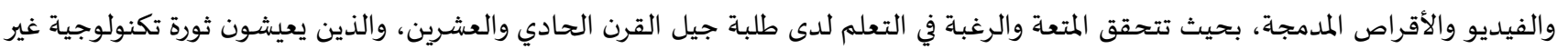

ونظراً لفاعلية بيئات التعلم الإلكترونية فقد تتابعت الدراسات التي تناولهها كمتغير مستقل لدراسة أثرها على كل من زيادة التحصيل وتنمية

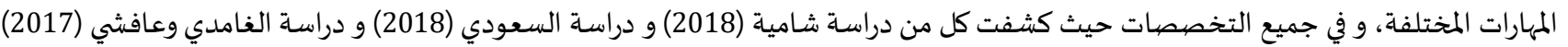
و دراسة شحاته(2017) ودراسة عقل وآخرون (2012) عن فاعلية البيئة التعليمية الإلكترونية في تنمية الجوانب المانب المهارية.

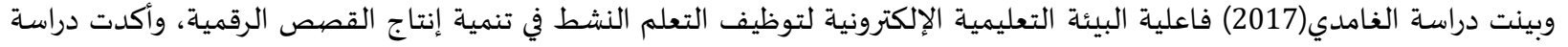

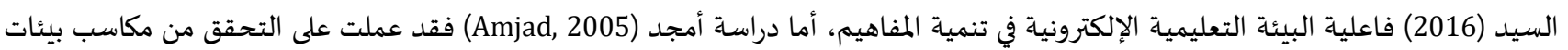
التعلم الإلكترونية.

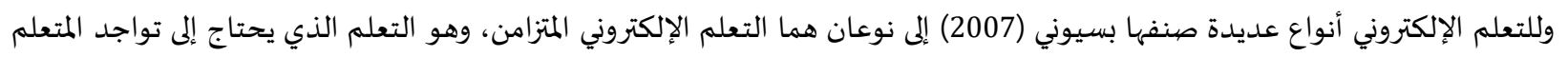

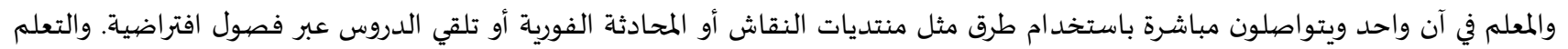

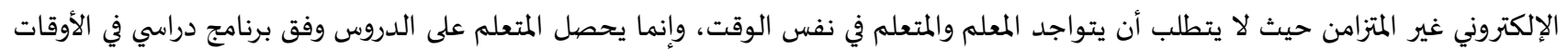

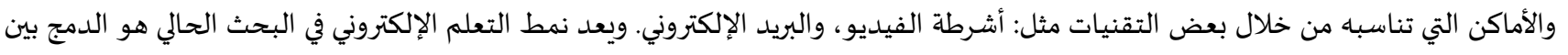

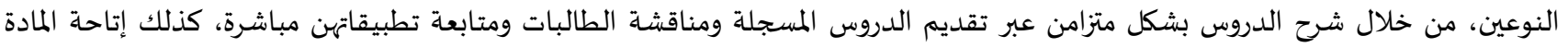

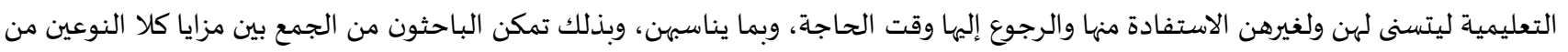

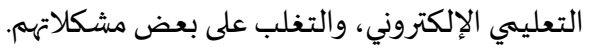

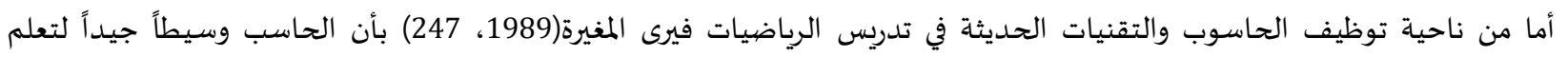
الرياضيات، ولعل من أهم الأسباب التي تدعو إلى استخدام الكمبيوتر، في تعليم وتعلم الرياضيات هو التحسن الكبير في اتجاهات المعلمين، والتلاميذ التيات 
نحو دراسة الرياضيات إضافة إلى حتمية مواجهة المدارس والمناهج للتطور المعرفي، والتقني الهائل، ومسايرته، فيما تتيح شبكة الإنترنت الفرصية

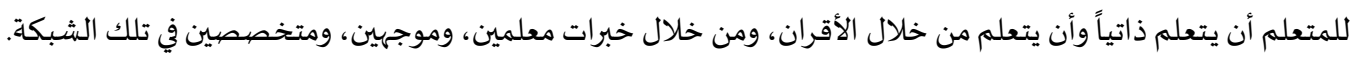

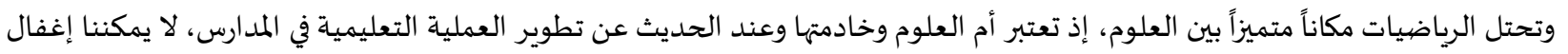
الدور الهام والفعال الذي تقوم به مادة الرياضيات في تنمية المهارات العقلية والحياتية للمتعلمين.

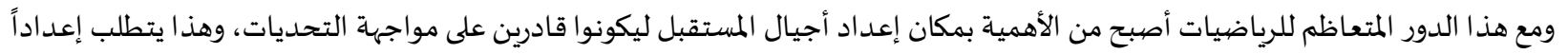
قوياً في الرياضيات، والبحث عن طرق تدريس جديدة وفعالة.

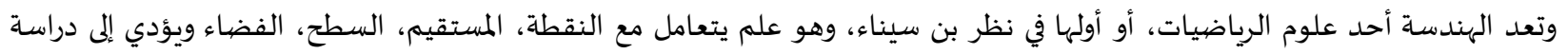

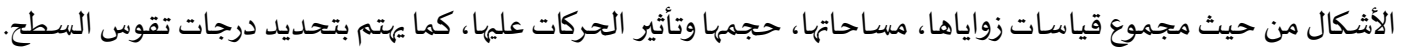

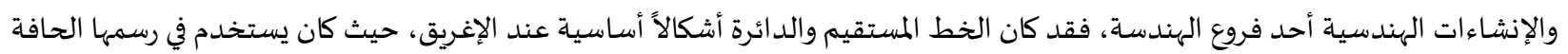

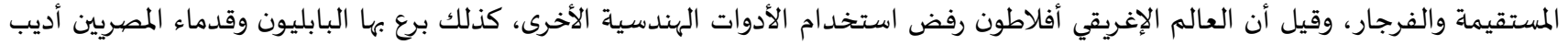

ولم تكن الإنشاءات الهندسية مجرد وصفات، بل براهين هندسية حقيقية مبررة بتطبيقات عملية؛ فطوال حقبة الرياضيات العربية الإسلامية،

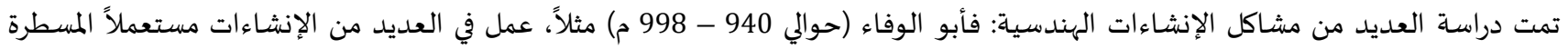

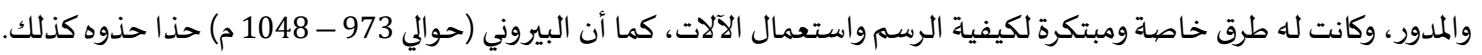

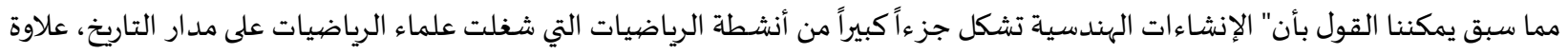

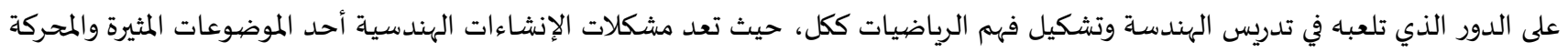

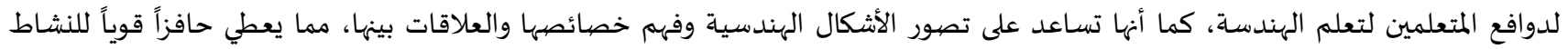

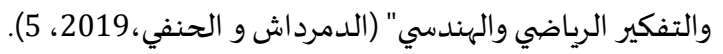

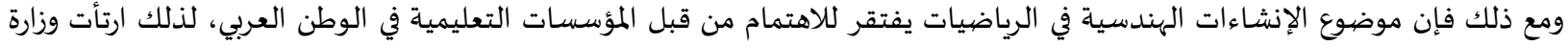

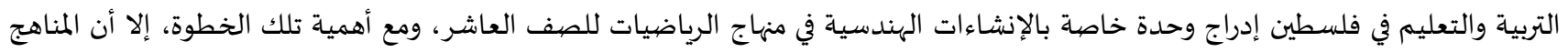

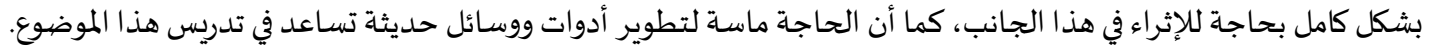

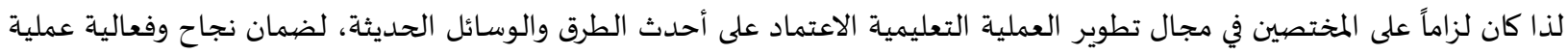
التدريس، وذلك بالاعتماد على التكنولوجيا الحديثة واستخدامها في التدريس، حيث يعتبر الحاسوب التعليمي أحد أبرز وأهم الوسائل التكنولوجية الترائ الحديثة المستخدمة في عملية التدريس الفعال. ولقد حقق الحاسوب نجاحاً كبيراً في تعليم الرياضيات وتعلمها وتعد البرمجيات الحاسوبية الجاهزة مجالاً هاماً لتطبيق التقنيات في تعليم المبال

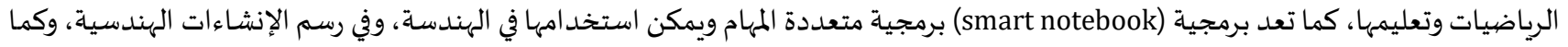

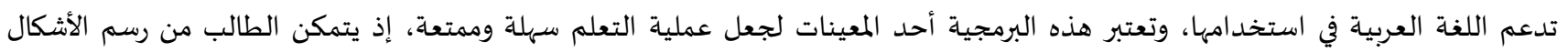

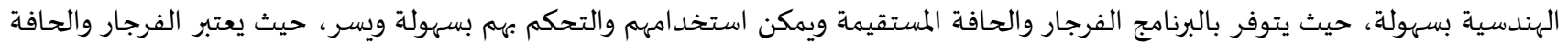

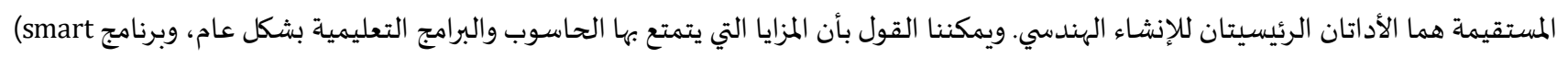
بشotebook)

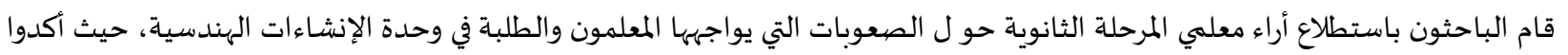

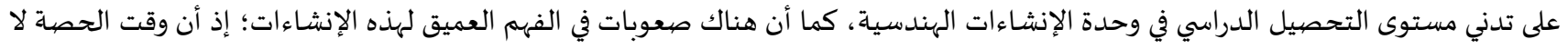

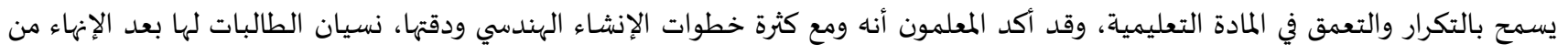
عرضها، لذلك ارتأى الباحثون ضرورة العمل الجاد لحل هذه المشكلة. وسعوا للبحث عن وسائل مساعدة للعمل على تنمية مهارات الإنشاءات الهندسية لدى الطلبة. ومما استجد على سير العملية التعليمية في المدارس والجامعات على مستوى فلسطين خاصة والعالم عامة في العام (2020م)، انتشار فايروس

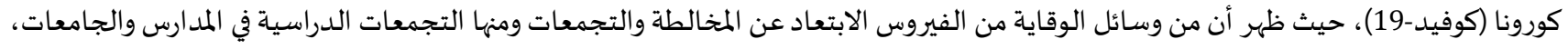

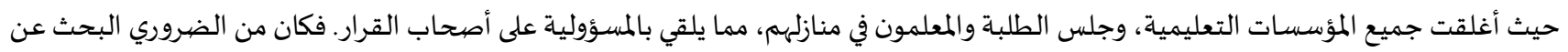
الطرق الملائمة لاستمرار العملية التعليمياة، وذلك بتحويل العملية التعليمية إلى التعليم الإلكتروني. 
لذلك ارتأى الباحثون ضرورة استخدام وسائل تكنولوجية حديثة تساعد على التواصل المستمر مع الطالبات ونقل الدروس إلى البيت، والتواصل

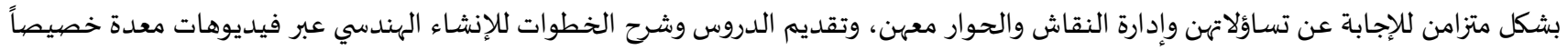

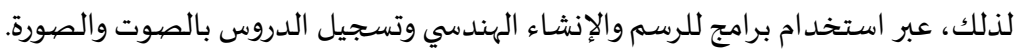

وقد سعى الباحثون للتوصل لأحدث التطبيقات التكنولوجية والبرامج الحاسوبية المستخدمة في العملية التعليمية، والتي يمكنها أن تخدم عملية

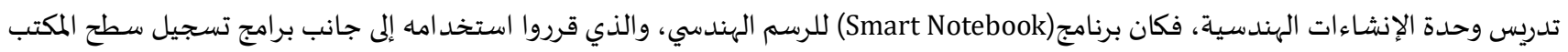

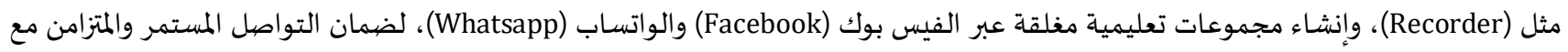

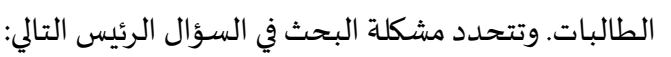

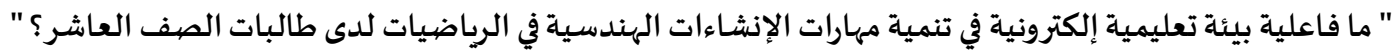

ويتفرع من السؤال الرئيس الأسئلة الفرعية الآتية:

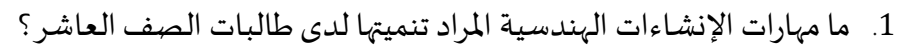

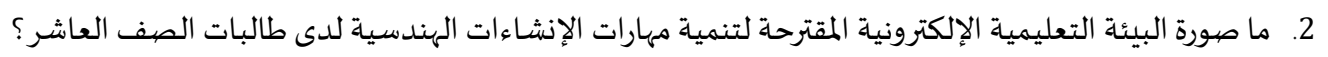

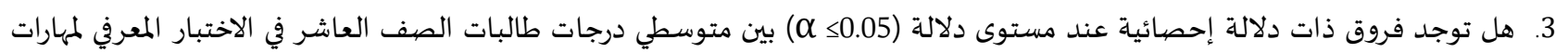

الإنشاءات الهندسية قبل وبعد التطبيق، تعزى للبيئة التعليمية الإلكترونية ؟

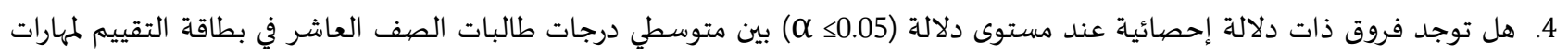

الإنشاءات الهندسية قبل وبعد التطبيق، تعزى للبيئة التعليمية الإلكترونية ؟

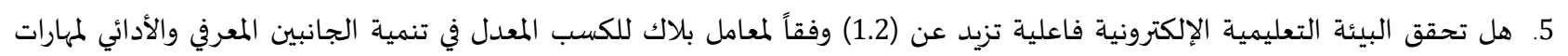

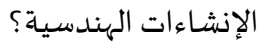

فرضيات الدراسة:

1. لا توجد فروق ذات دلالة إحصائية عند مستوى دلالة(0.05 م) بين متوسطي درجات طالبات الصف العاشر في الاختبار المعرفي لمهارات

الإنشاءات الهندسية قبل وبعد تطبيق بيئة التعلم الإلكترونية.

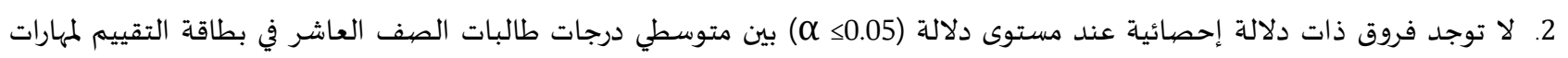

الإنشاءات الهندسية قبل وبعد تطبيق بيئة التعلم الإلكترونية.

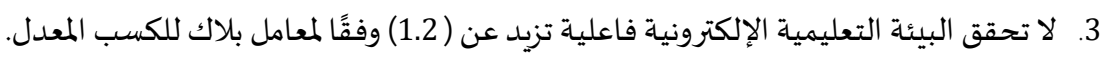

أهداف الدراسة:

هدف هذا البحث إلى تحقيق ما يلي: 1. الكشف عن الفروق ذات الدلالة الإحصائية بين متوسطي درجات طالبات الصف العاشر في الاختبار المعرفي لمهارات الإنشاءات الهندسية قبل وبعد التطبيق. 2. الكشف عن الفروق ذات الدلالة الإحصائية بين متوسطي درجات طالبات الصف العاشر في بطاقة التقييم لمهارات الإنشاءات الهندسية قبل وبعد التطبيق. 3. الكشف عن فاعلية بيئة التعلم الإلكترونية في تنمية مهارات الإنشاءات الهندسية في الجانبين المعرفي والأدائي لدى طالبات الصف العاشر.

أهمية الدراسة:

تتمثل أهمية البحث أنهاه قد: 1. يقدم بيئة تعليمية إلكترونية تحتوي فيديوهات شارحة للإنشاءات الهندسية المتضمنة في منهاج الصف العاشر في مادة الرياضيات كدليل

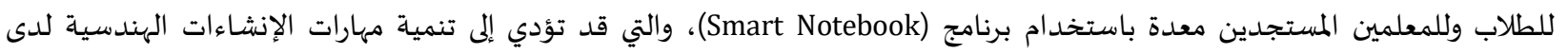

$$
\text { المتعلمين، وتمكنهم من التعلم الذاتي. }
$$

2. يقدم أدوات قياس (اختبار معرفي وبطاقة ملاحظة) مبنية بطريقة علمية ومنهجية، تتسم بالصيدق والثبات. 3. قد يفيد الطلبة في رسم الإنشاءات الهندسية باستخدام برنامج (Smart Notebook)، كما قد فئد تكون اتجاهات إيجابية لديهم نحو التعلم. 4. قد يفيد المختصين في تخطيط وتطوير المناهج لتوسيع نطاق تدريس الإنشاءات الهندسية في المقررات الدراسية. 
حدود الدراسـة:

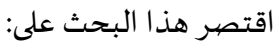

الحد المكاني: مدرسة على بن أبي طالب الثانوية للبنات التابعة لوزارة التربية والتعليم بمنطقة شرق غزة. الحد الزماني: الفصل الدراسي الثاني (2020-2019).

الحد البشري: طالبات الصفف العاشر الأسـاسي في مدرسة على بن أبي طالب الثانوية للبنات وعددهن (22) طالبة. الحد الموضوعي: فاعلية بيئة تعليمية إلكترونية في تنمية مهارات الإنشاءات الهندسية من منهاج الرياضيات، الجزء الثاني، للصف العاشر الأساسي.

مصطلحات الدراسة:

ورد في البحث مجموعة من المصطلحات الجوهرية تم تعريفها إجرائياً، وجاءت على النحو التالي:

• • ب البيئة التعليمية الإلكترونية:

ويعرفها عبد المجيد وإبراهيم (2018 ) بأها "شكل من أشكال التعلم عبر شبكة الإنترنت يتم من خلالها إدارة عملية التعلم وتنظيمها بحيث تقدم

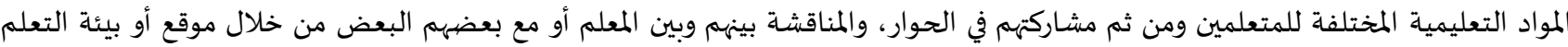

التشاركي".

ويعرفها الباحثون إجرائياً بأها بيئة تقنية مرنة، تتخطى حدود الزمان والمكان يتم من خلالها تناول مهارات الإنشاءات الهندسية لطالبات الصف

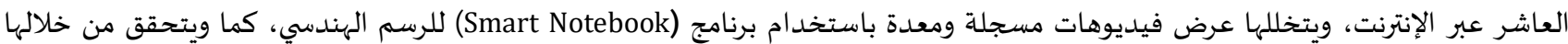

الحوار والنقاش، وتتقدم من خلالها الطالبات للاختبارات الإلكترونية لقياس مدى تنمية المعارف والمهارات المتعلقة بالإنشـاءات الهندسية.

$$
\text { مهارات الإنشاءات الهندسية: }
$$

يعرف الإنشاء الهندسي على أنه "مجموعة من الإجراءات الماءنات المعيارية لإنشاء كيانات هندسية مثل منصف زاوية باستخدام الفرجار والحافة المستقيمة فقط " (Lim, 1997, p138).

ويعرفها عبيد والمفتى ونوح (1988، ص 101) على أنها "عملية هندسية يتم بها إجراء معين باستخدام الحافة المستقيمة والفرجار، وذلك دون

استخدام القياس في الأطوال أو الزوايا".

ويعرفها الباحثون إجرائياً بأهها تنفيذ إجراءات معيارية لإنشاء كيانات هندسية باستخدام الحافة المستقيمة والفرجار فقط، دون استخدام مقايس للأطوال أو الزوايا، ويتم حساب مهارات الإنشاءات الهندسية من خلال الدرجة التي تحصل عليها الطالبة على الاختبار المعرفي وبطاقة التقييم المستخدمة في البحث الحالي.

إجراءات الدراسـة:

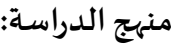

استخدم الباحثون في هذه الدراسة كل من المنهج الوصفي التحليلي، ويعرف الجبوري (Al Gbory, 2012, p179) المنهج الوصفي التحليلي بأنه "وصف دقيق ومنظم وأسلوب تحليلي للظاهرة أو المشكلة المراد بحثها، من خلال منهجية عملية للحصول على نتائج عملية وتفسيرها بطريقة موضوعية

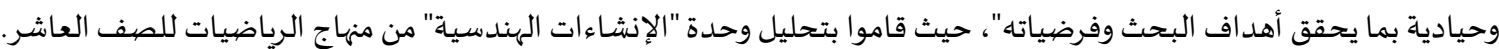
كما استخدم الباحثون المنهج شبه التجريبي بتصميم المجموعة التجريبية الواحدة ذات القياس القبلي والبعدي، والذي يعرفه الجرجاوي (Al Gergawi, 2010, p76)

اختار الباحثون عيّنة من طالبات مدرسة علي بن أبي طالب الثانوية للبنات بطريقة قصدية، وقد تكوّنت العينة من (22) طالبة من طالبات

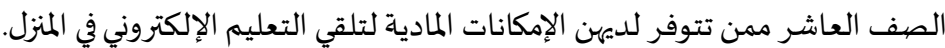

$$
\text { أدوات الدراسـة: }
$$

بناء أدوات الدراسـة:

لبناء أدوات الدارسة قام الباحثون بتحليل الوحدة السادسة (وحدة الإنشاءات الهندسية ) من كتاب الرياضيات للصف العاشر، وذلك لتحديد الأهد اف التعليمية، والتي سيعد الاختبار المعرفي بناءً عليها، كذلك لتحديد مهارات الإنشاءات الهندسية المطلوبة في منهاج الصف العاشر. 
أولاً: بناء الاختبار المعرفي لمهارات الإنشاءات الهندسية:

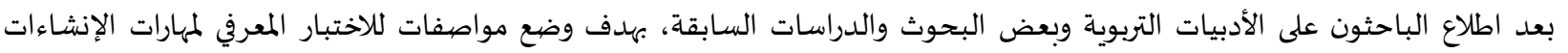

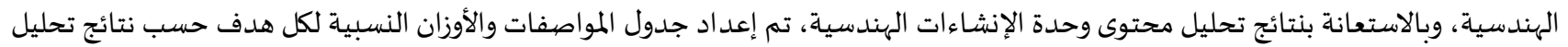

المحتوى، وفي ضوء ما سبق قام الباحثون بإعداد اختبار معرفي لمهارات الإنشاءات الهندسية، وقد اتبعوا الإجراءات التالية لتصهميم وبناء الاختبار: 1. 1 الهدف من الاختبار:

تم تحديد الهدف من الاختبار بقياس الجانب المعرفي لمهارات الإنشاءات الهندسية لدى طالبات الصف العاشر، وقد تم تقسيم أهداف المادة

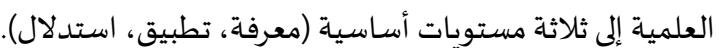

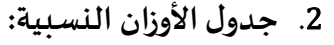

قام الباحثون بإعداد الاختبار بناءً على جدول الأوزان النسبية الذي أعد في ضوء تحليل المحتوى. كما في الجدول (1). وقد كان هناك بعض الفروق بين الوزن النسبي للأهداف في المنهاج، وبين تمثيلها بأسئلة الاختبار، وذلك لانتماء بعض الأسئلة لأكثر من هدف،

حيث قام الباحثون باحتسابها وفق الهدف العام للسؤال.

جدول (1): جدول الأوزان النسبية للاختبار المعرفي

\begin{tabular}{|c|c|c|c|c|c|c|}
\hline رمز السؤال المنتمي لمستوى الهدف & للنسئة المئوية & عدد الأسئلة & للألسبة المئوّية & 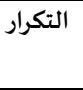 & مستوى الأهداف & 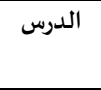 \\
\hline السؤال الأول: 1-3-11-12 & $\% 17.3$ & 4 & $\% 11.8$ & 9 & المعرفة & \\
\hline السؤال الأول : 13-5 & $\% 17.3$ & 4 & $\% 13$ & 10 & التطبيق & إنشاءات \\
\hline السؤال الثاني: 1-4 & & & & & & هندسية \\
\hline السؤال الأول : 7-4 & $\% 8.7$ & 2 & $\% 10.5$ & 8 & 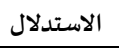 & $(1)$ \\
\hline السؤال الأول : 15-16 & $\% 8.7$ & 2 & $\% 3.9$ & 3 & المعرفة & إنشاءات \\
\hline السؤال الثاني: 2-3-3 & $\% 13$ & 3 & $\% 11.8$ & 9 & التطبيق & هندسية ل \\
\hline السؤال الأول : 10 & $\% 4.4$ & 1 & $\% 3.9$ & 3 & 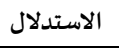 & (2) \\
\hline السؤال الأول : 6-14 & $\% 8.7$ & 2 & $\% 10.5$ & 8 & المعرفة & \\
\hline السؤال الثاني: 5 & $\% 4.4$ & 1 & $\% 17.1$ & 13 & التطبيق & المثلث المثل \\
\hline السؤال الأول : 8-2 & $\% 8.7$ & 2 & $\% 3.9$ & 3 & الاستدلال & \\
\hline- & $\% 0$ & - & $\% 2.6$ & 2 & المعرفة & المضلعات \\
\hline السؤال الأول : 9 & $\% 8.7$ & 2 & $\% 9.2$ & 7 & التطبيق & 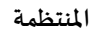 \\
\hline \multicolumn{7}{|l|}{ السؤال الثاني: } \\
\hline \multirow[t]{2}{*}{ - } & $\% 0$ & - & $\% 1.3$ & 1 & الاستدلال & \\
\hline & $\% 100$ & 23 & $\% 100$ & 76 & \multicolumn{2}{|c|}{ المجموع } \\
\hline
\end{tabular}

3.

تم وضع نوعين من الأسئلة، الأول موضوعي من نوع اختيار من متعدد، ويتكون من (16) فقرة، لكل فقرة أربعة بدائل، والثاني مقالي يتكون من (7) فقرات لتنفيذ مهارات الإنشاءات الهندسية المطلوبنة.

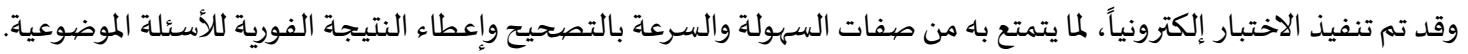

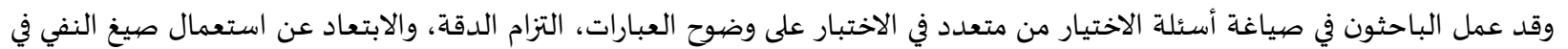
بداية العبارة المراد الإجابة عنها.

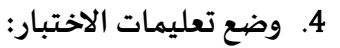
وقد كتب الباحثون نبذة مختصرة عن الدراسة وتعليمات الاختبار الإلكتروني في بداية النموذج، بحيث ترشد الطالبات إلى كيفية الإجابة الصحيحة عن مفردات الاختبار. 5. وللتأكد من أن الاختبار يقيس ما وضئع لقياسها، والاطمئنان بأنه يمكن بناء تفسيرات معينة بناءً على درجات الاختبار، قام الباحثون بعرض الاختبار على مجموعة من المحكمين المختصين في مجال المناهج وطرق التدريس، ومدرسي رياضيات، ومشرفين، وقد بلغ عددهم(6) محكمين، وذلك للأخذ بآرائهم حول: الصياغة اللغوية السليمة. مطابقة الأسئلة للمنهاج (وحدة الإنشاءات الهندسية من كتاب الرياضيات للصف العاشر). 
مناسبة البد ائل لكل فقرة من فقرات الاختبار.

وقد تمّ إجراء التعديلات على بعض فقرات الاختبـار ، وذلك أخذاً بما هو مناسب من ملاحظات المحكمين، وذلك بالتشـاور مع المشرفين.

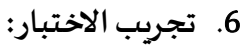

طبّق الباحثون الاختبار على عينة استطلاعية من طالبات الصف الحادي عشر، قوامها (36) طالبة، حيث قام الباحثون بوضع رابط الاختبار في أحد مجموعات الصف الحادي عشر الإلكترونية، وقد أجريت التجربة الاستطلاعية لاختبار مهارات الإنشاءات الهندسية عئهية بهدف:

التأكد من صدق وثبات الاختبار.

حساب معاملات الصعوبة والتمييز لفقرات الاختبار.

التأكد من صبدق وثبات الاختبار:

• صدق الاختبار: وهو أن يقيس الاختبار ما صيمم لقياسـ (فرج، 1999: 254) لذلك اتبع الباحثون مؤشرات عدة للتحقق من صديد الاختبار، وهي: 1. صيدق المحكمين: وللتأكد من أن الاختبار يقيس ما وضع لقياسـ، قام الباحثون بعرض الاختبار المكون من (23) فقرة، على مجموعة من المحكمين

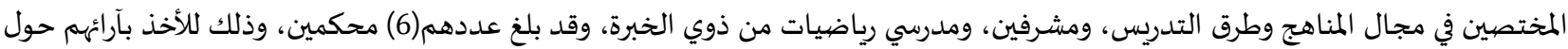

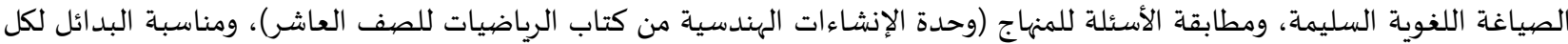
فقرة من فقرات الاختبار. وقد تم الأخذ بما هو مناسب من ملاحظات المحكمين.

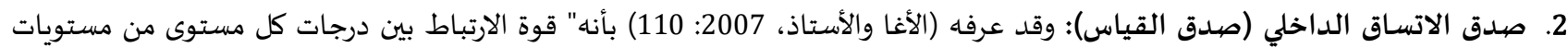
الأهداف ودرجة الاختبار الكلية وكذلك درجة ارتباط كل سؤال من أسئلة الاختبار بمستوى الأهداف الكلي الذي تنتمي إليه." لذلك قام الباحثون بالتحقق من صدق الاتساق الداخلي بعد تطبيق الاختبار على العينة الاستطلاعية، حيث قاموا بحساب معامل ارتباط بيرسون بين كل فقرة من فقرات الاختبار وبين درجة البعد الذي تنتمي إليه، كذلك حساب معامل ارتباط بيرسون بين درجة البعد والدرجة الكلية للاختبار، والجداول التالية توضح ذلك: جدول (2): يوضح معاملات الارتباط بين كل فقرة من فقرات اختبار الإنشاءات الهندسية وبين المستوى الذي تنتهي إليه

\begin{tabular}{|c|c|c|c|c|c|}
\hline معامل الارتباط & رقم الفقرة & البعد & معامل الارتباط & رقم الفقرة & البعد \\
\hline $0.388^{*}$ & 5 & \multirow{3}{*}{ مستوى } & $0.347^{*}$ & 1 & \multirow{4}{*}{ مستوى } \\
\hline $0.498^{* *}$ & 9 & & $0.348^{*}$ & 3 & \\
\hline $0.380^{*}$ & 13 & & $0.422^{*}$ & 6 & \\
\hline $0.543^{* *}$ & 17 & \multirow{10}{*}{ التطبيق } & $0.461^{* *}$ & 11 & \\
\hline $0.434^{* *}$ & 18 & & 0.319 & 12 & \multirow{4}{*}{ المعرفة } \\
\hline $0.547^{* *}$ & 19 & & 0.195 & 14 & \\
\hline $0.471^{* *}$ & 20 & & $0.469^{* *}$ & 15 & \\
\hline $0.559^{* *}$ & 21 & & $0.433^{* *}$ & 16 & \\
\hline 0.074 & 22 & & $0.523^{* *}$ & 2 & \\
\hline \multirow[t]{4}{*}{$0.446^{* *}$} & 23 & & $0.645^{* *}$ & 4 & \\
\hline & & & $0.653^{* *}$ & 7 & مستوى \\
\hline & & & $0.606^{* *}$ & 8 & الاستدلال \\
\hline & & & $0.638^{* *}$ & 10 & \\
\hline
\end{tabular}

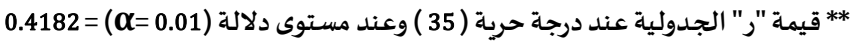

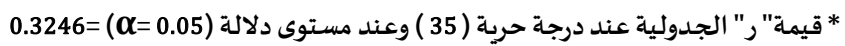

يتضح من جدول (2) أن جميع فقرات الاختبار جاءت مرتبطة مع الدرجة الكلية للمستوى الذي تنتمي إليه، عدا الفقرات (22- 14-12)، لذلك تمت إعادة صياغتهم نظراً لأهميتهم. وبذلك يمكن الاستدلال بأن جميع فقرات الاختبار منتمية لمستواها المعرفي، و أن الاختبار يتسم بالاتساق الداخلي.

\begin{tabular}{|c|c|c|}
\hline مستوى الدلالة & معامل الارتباط الكلي & المجال \\
\hline دالة عند (0.01) & $0.700^{* *}$ & مستوى المعرفة \\
\hline دالة عند (0.01) & $0.923^{* *}$ & مستوى التطبيق \\
\hline دالة عند (0.01) & $0.795^{* *}$ & مستوى الاستدلال \\
\hline
\end{tabular}

يوضح الجدول(3) أن جميع معاملات الارتباط لكل المستويات دالة إحصائياً، مما يعني أن الاختبار يتمتع بصدةق بنائي مناسب، وأنه جاهز للتطبيق. ثبات الاختبار: ويقصد باه الحصول على نفس النتائج عند تكرار القياس باستخدام نفس الأداة في نفس الظروف" (الأغا، 1997)، وقام الباحثون

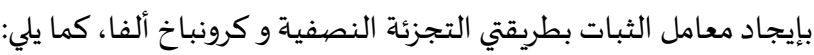


1. طريقة التجزئة النصفية: وقد تم تجزئة فقرات الاختبار إلى نصفين ( فقرات فردية، وفقرات زوجية، و تم حساب ثبات الاختبار بطريقة التجزئة

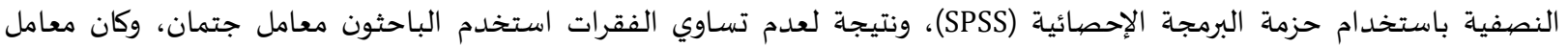

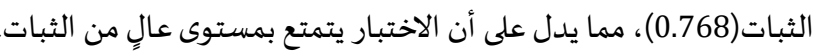

2. طريقة معادلة كرونباخ ألفا: واستخدم الباحثون معادلة كرونباخ الفا لقياس الثبات، نظراً لتنوع أسئلة الاختبار بين الموضيوعية و المقالية،

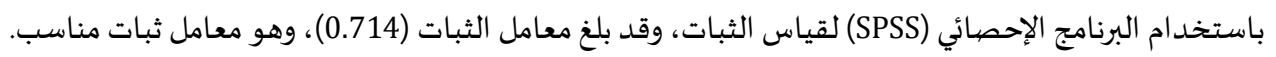

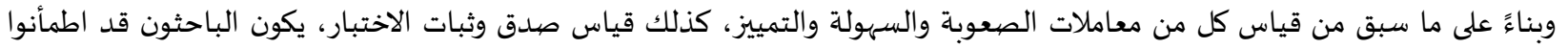
لإمكانية تطبيق الاختبار على عينة الدّراسة.

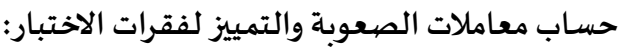
• معامل الصعوبة: ويعرِف معامل الصعوبة أنه " النسبة المئوية من الطالبات اللواتي أجبن عن السؤال إجابة خاطئة مقسوم على عدد الطالبات

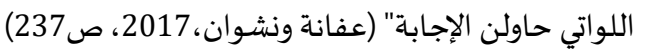
وقد قام الباحثون بحساب درجة صعوبة كل فقرة من فقرات الاختبار، حيث تراوحت بين (0.25-0.67) بمتوسط (0.42)، مما يشير إلى أن جميع فقرات الاختبار تقع ضمن المستوى المطلوب لدرجة الصعوبة والذي يتراوح بين (0.8-0.2). معامل التمييز: وهو "قدرة الفقرة على التمييز بين الطالبات اللواتي يتمتعن بقدر أكبر من المعارف والطالبات الأقل قدرة في مجال معين من

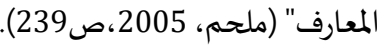
وقام الباحثون بحساب معامل التمييز لفقرات الاختبار، حيث تراوحت بين (0.12-0.72) بمتوسط بلغ (0.37)، مما يشير إلى أن جميع فقرات الاختبار تقع ضمن المستوى المطلوب لدرجة التميز. وبناءً على ذلك تم قبول جميع فقرات الاختبار، حيث وقعت ضمن المستوى المطلوب للصعوبة والتمييز.

ثانياً: بناء بطاقة تقييم مهارات الإنشاءات الهندسية:

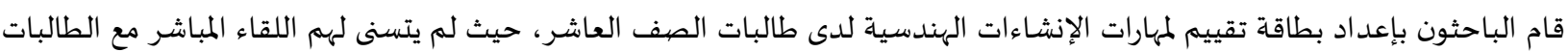
لملاحظة أدائهن؛ بسبب إغلاق المؤسسات التعليمية بسبب انتشار فايروس كورونا (كوفيد-19)، فقمن بإرسال تطبيقاتهن إلكترونياً، وقد اتِّع الباحثون

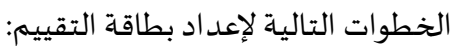
1. 2. 3. 4. ت ثبات بطاقة التقييم. 1. تحديد الهدف من بطاقة التقييم: وتهدف بطاقة التقييم لقياس مدى امتلاك طالبات الصف العاشر لمهارات الإنشاءات الهندسية المقررة معهم في منهاج الرياضيات. 2. إعداد بطاقة التقييم: بعد الاطلاع على الأدب التربوي والدراسات السابقة المتعلقة بالمهارات وبالإنشاءات الهندسية، كدراسـة النجار (2012 م)، والدمرداش والحنفي (2018 م)، وأبو عميرة (1993م)، ودراسة اتاسوري وكربوز (2018 م)، قام الباحثون بإعداد بطاقة التقييم وذلك بالاعتماد

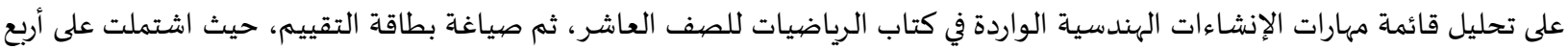

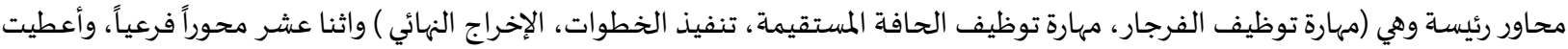

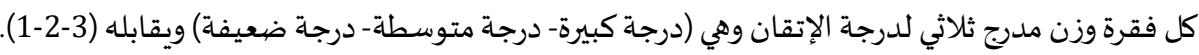
3. صهدق بطاقة التقييم: قام الباحثون بالتأكد من صديدق بطاقة التقييم عن طريق: صددق المحكمين: قام الباحثون بعرض بطاقة التقييم في صورتها الأولية على مجموعة من الخبراء والمختصين في المناهج وطرق التدريس،

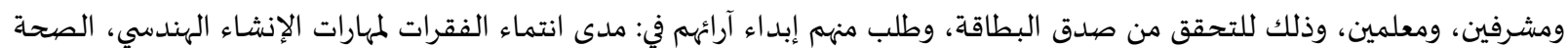

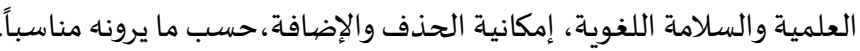

ثم قام الباحثون بإجراء بعض التعديلات المطلوبة على بطاقة التقييم، وتكونت الصيورة النهائية من (4) محاور رئيسة و (12) مهارة فرعية. صيدق الاتساق الداخلي: قام الباحثون بتطبيق البطاقة على عينة استطلاعية مكونة من (20) طالبة من طالبات الصف الحادي عشر،

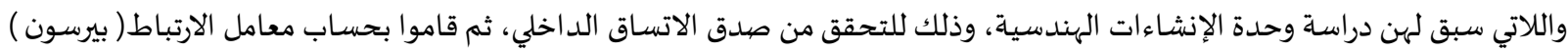

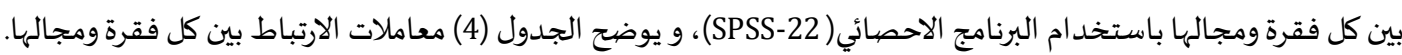


جدول(4): قيم معامل ارتباط بيرسون بين كل فقرة من فقرات البطاقة والدرجة الكلية للمجال

\begin{tabular}{|c|c|c|c|}
\hline 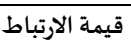 & 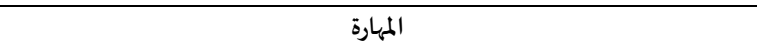 & 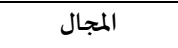 & م \\
\hline $0.837^{* *}$ & يوضح الرسم تركيز الفرجار بشكل دقيق في المكان المناسب. & & 1 \\
\hline $0.843^{* *}$ & يوضح الرسم ثبات فتحة الفرجار عند تكرار رسم الأقواس. & 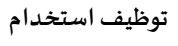 & 2 \\
\hline $0.670^{* *}$ & 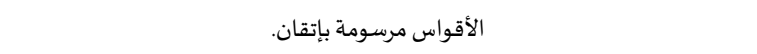 & 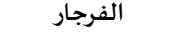 & 3 \\
\hline $0.796^{* *}$ & يوضح الرسم أن النقاط محددة على خط الأعداد باستخدام الفرجار، و دون الاستعانة & & 4 \\
\hline $0.833^{* *}$ & النقاط موصولة بدقة باستخدام الحافة المستقيمة. & توظيف استخدام & 5 \\
\hline $0.685^{* *}$ & يحتوي الإنشاء على الخطوط اللازمة فقط، وبما هو مناسب. & 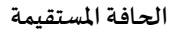 & \\
\hline $0.724^{* *}$ & يتضح من الرسم ابتداء الإنشاء بصورة صحيحة. & & 6 \\
\hline $0.794^{* *}$ & خطوات الإنشاء منفذة بشكل متسلسل. & 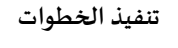 & 7 \\
\hline $0.860^{* *}$ & لا توجد خطوات عشوائية أو غير لازمة مضافة للإنشاء المطلوب. & & 8 \\
\hline $0.877^{* *}$ & تم تبرير خطوات الإنشاء رياضياً (بالبرهان). & & 9 \\
\hline $0.711^{* *}$ & خطوات تنفيذ الإنشاء (كتابةً) مصاغة بصورة صحيحة. & & 10 \\
\hline $0.948^{* *}$ & يتميز الإنشاء بالنظافة والترتيب. & 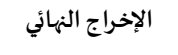 & 11 \\
\hline $0.888^{* *}$ & الإنشاء منفذ بالكامل حسب المطلوب. & & 12 \\
\hline
\end{tabular}

0.455 قيمة (ر ) الجدولية عند درجة حرية (19) ومستوى دلالة (0.05)

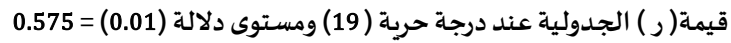

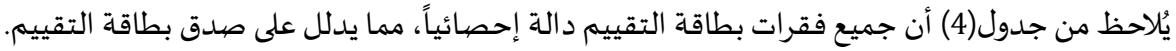

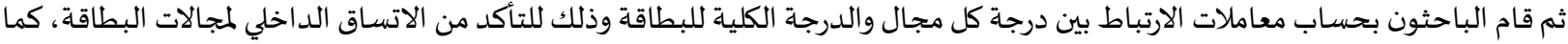

هو موضح في جدول (5).

جدول (5): معاملات الارتباط بين كل مجال من مجالات البطاقة والدرجة الكلية للبطاقة

\begin{tabular}{|c|c|c|}
\hline 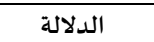 & قيمة الارتباط & المجال \\
\hline دال عند(0.01) & $0.922^{* *}$ & توظيف استخدام الفرجار \\
\hline دال عند(0.01 ) & $0.823^{* *}$ & توظيف استخدام الحافة المستقيمة \\
\hline دال عند(0.01 ) & $0.877^{* *}$ & ت ت تنفيذ الخطوات \\
\hline دال عند(0.01 ) & $0.924^{* *}$ & الإخراج النهائي \\
\hline
\end{tabular}

ويتضح من الجدول (5) أن جميع محاور بطاقة التقييم مرتبطة بالدرجة الكلية للبطاقة، ارتباطاً ذو دلالة إحصائية، وهذا يدل على صدق الاتساق الداخلي لبطاقة التقييم.

4. ثبات بطاقة التقييم: قام الباحثون بحساب معامل الثبات بعدة طرق، متمثلة في التجزئة النصفية و كرونباخ ألفا، وثبات الملاحظين، كما يلي:

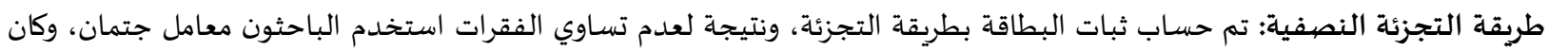

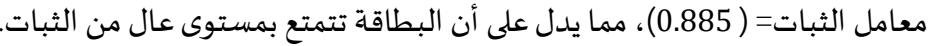
طريقة معادلة كرونباخ ألفا: واستخدم الباحثون معادلة كرونباخ لقياس الثبات، باستخدام البرنامج الإحصائي (SPS-22) لقياس الثبات، وقد بلغ معامل الثبات (0.849)، وهو معامل ثبات مناسب. • اتفاق الملاحظين: قام الباحثون بالتأكد من ثبات البطاقة، من خلال قيام أحد الباحثين بتطبيق بطاقة التقييم على (10) طالبات، ثم قام باحث أخر بالتقييم لحساب معامل الاتفاق، وذلك باستخدام المعادلة التالية (Cooper, 1973, p27).

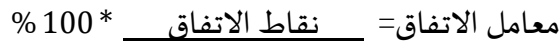

(نقاط الاتفاق + نقاط الاختلاف)

وكانت النتيجة كما هي موضحة في الجدول (6) : 
جدول(6): معامل الاتفاق بين المقيم الأول والثاني ببطاقة التقييم

\begin{tabular}{|c|c|c|c|c|c|}
\hline معامل الاتفاق & الاختلاف & الاتفاق & المقيم الثاني & المقيم الأول & الطالبة \\
\hline$\% 93.75$ & 1 & 15.00 & 16.00 & 15.00 & 1 \\
\hline$\% 95.3$ & 1 & 20.00 & 21.00 & 20.00 & 2 \\
\hline$\% 95.6$ & 1 & 22.00 & 23.00 & 22.00 & 3 \\
\hline$\% 92.00$ & 2 & 23.00 & 23.00 & 25.00 & 4 \\
\hline \%95 & 1 & 19.00 & 19.00 & 20.00 & 5 \\
\hline$\% 88$ & 2 & 16.00 & 16.00 & 18.00 & 6 \\
\hline$\% 100$ & 0 & 38.00 & 38.00 & 38.00 & 7 \\
\hline$\% 91$ & 2 & 19.00 & 21.00 & 19.00 & 8 \\
\hline$\% 92$ & 2 & 22.00 & 24.00 & 22.00 & 9 \\
\hline$\% 93.75$ & 1 & 15.00 & 15.00 & 16.00 & 10 \\
\hline
\end{tabular}

من الجدول (6) نلاحظ أن أعلى نسبة للاتفاق بين الملاحظين هي(100\%) ، وأقل نسبة للاتفاق هي (88\%)، وأن متوسط الثبات الكلي هو \%) (94.2، وبذلك يمكننا القبول بثبات الملاحظين حيث زادت نسبته عن (80 \%). وبناءً على ما سبق من قياس كل من صدق وثبات البطاقة، يمكن تطبيق بطاقة التقييم على عينة الدراسة.

تصميم بيئة التعلم الإلكترونية: تعتبر البيئة التعليمية الإلكترونية بيئة تقنية يتم من خلالها تقديم الموضيوعات الدراسية بطريقة تفاعلية وبأسلوب شيق، وقد عرفها (عقل وآخرون، 2013) بأنها منظومة متكاملة وتفاعلية لتقديم المقرر في ضوء استراتيجية تعليمية محددة.

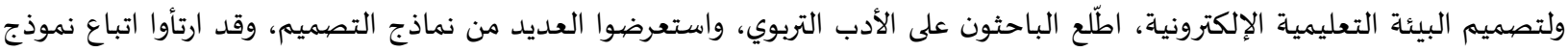

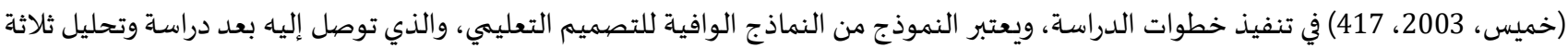

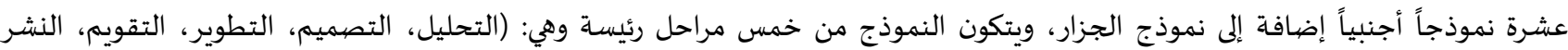

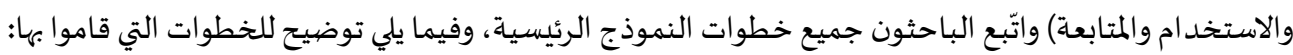
المرحلة الأولى: مرحلة التحليل : وقد قام الباحثون بالخطوات التالية، لإجراء عملية التحليل: تحليل المشكلة وتقدير الحاجات: وقد تمثلت المشكلة في تنمية مهارات الإنشاءات الهندسية لدى طالبات الصف العاشر. تحديد الأهداف العامة التي ينبغي أن يتمكن منها المتعلمون : وقد قام الباحثون بتحليل محتوى وحدة الإنشاءات الهندسية للصف العاشر، وأعدوا قائمة بالأهداف المتوفرة في الوحدة، والتي يسعون لتحقيقهي التهيا. تحديد طبيعة المشكلة، وأسبابها: لاحظ الباحثون وجود مشكلة لدى الطالبات تمثّلت في:

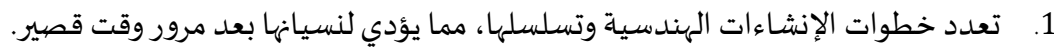

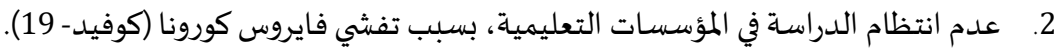
اقتراح الحلول التعليمية الممكنة والمناسبة للمشكلات: وقد وضع الباحثون بعض الحلول، تمثلت في:

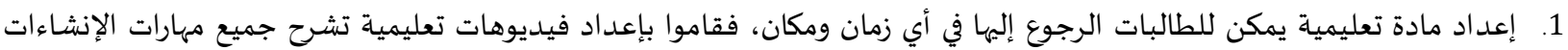
الهندسية باستخدام برنامج (smart notebook). 2. التواصل مع الطالبات عبر بيئة تعليمية إلكترونية، لشرح الدروس، وإدراج الفيديوهات المعدة، والتواصل المستمر للمناقشة وإعطاء التغذية الراجعة والتقييم وإجراء الاختبارات.

تحليل خصيائص المتعلمين وسلوكههم المدخلي: ارتأى الباحثون ضرورة أن تكون عينة الدراسة من الطالبات اللاتي لديهن القدرة على التواصل الإلكتروني، من خلال توفر جهاز متصل بالإنترنت، كذلك امتلاك مهارة استخدام الانترنت، والتعامل مع تطبيقات جوجل درايف ( Google

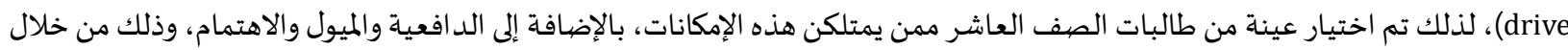

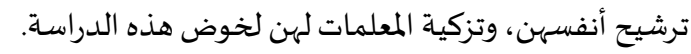
تحليل الموارد في البيئة التعليمية: وقد تمثلت هذه الموارد في:

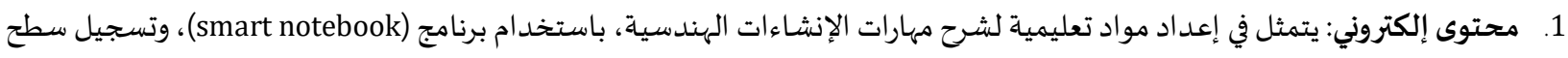
المكتب باستخدام (smart recorder)، كذلك استخدام (VSDC Free Video Editor) ) لمونتاج الفيديو. 2. بيئة إلكترونية : وشملت تطبيقات (Whatsapp و (Gocebook)، كذلك تطبيقات (Google drive) لإجراء عملية التقويم وتنفيذ الاختبارات. 
المرحلة الثانية: مرحلة التصيميم: وقد قام الباحثون باتباع خطوات النموذج في مرحلة التصيميم، وتمثلت في: تصيميم الأهداف السلوكية: وقد قام الباحثون بتحليل وحدة الإنشاءات الهندسية لاستنتاج الأهداف السلوكية، حيث صنفوا الأهداف وفق مستويات العمق المعرفي لنورمان ويب وهي (المعرفة، التطبيق، الاستدلال)، ثم قاموا بإعداد جدول الأوزان النسبية لتحديد الوزن النسبي لكل

هدف في الوحدة، كما هو موضح في جدول (2).

تصميم أدوات القياس: وتم تصميمها حسب نموذج خميس (2003) وفقاً للخطوات التالية:

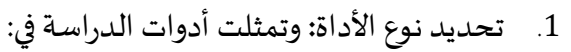

اختبار معرفي لمهارات الإنشاءات الهندسية.

بطاقة تقييم المنتج، لمهارات الإنشاءات الهندسية.

2. تحديد عدد الأسئلة المناسبة لكل هدف : وقد تم بناء جدول المواصفات المئداء لمعرفة الوزن النسبي لكل هدف، وتمثيلها في أسئلة الاختبار.

3. صياغة الأسئلة صياغة صحيحة وواضحةة، وقد تم عرض الأسئلة على مجموعة من المحكمين للتأكد من ذلك.

تصميم إستر اتيجية تنظيم المحتوى وتتابع عرضسه: وقد التزم الباحثون بتنظيم وتتابع موضوعات وحدة الإنشاءات الهندسية في كتاب

الرياضيات، حيث اتسم ترتيبها بالمنطقية.

تحديد طرق واستر اتيجيات التعليم: واتِّع الباحثون إستراتيجية الجمع بين العرض والاكتشاف.

تصميم سيناريو التفاعلات التعليمية:حيث قام الباحثون بتحديد زمن مناسب للحصة،، بحيث تتواجد جميع الطالبات في مجموعة الواتس

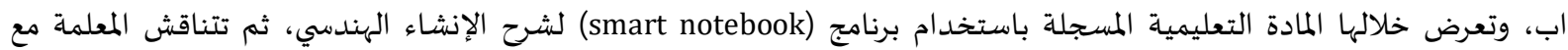
الطالبات بمحتواها، كما تستثير تفكيرهم للاكتشاف والتوصل لحلول لمشكلات مشابهة يتم طرحها، ثم تقوم الطالبات بتنفيذ مهارات

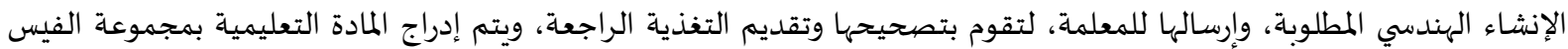

بوك، لكي يتسنى للجميع الرجوع إليها والاستفادة منها.

اختيارمصيادر التعلم ووسائله المتعددة : والتي تمثلت في فيديوهات تعليمية قام الباحثون بإعدادها وتسجيلها، ومجموعات حاضنة للنقاش والتفاعل متمثلة في مجموعة (Facebook)، ومجموعة (whatsapp)، كذلك استخدام تطبيقات (Google Drive) لتنفيذ الاختبارات، واستقبال أعمال الطالبات.

المرحلة الثالثة: مرحلة التطوير: ويتم بها تحويل التصميمات والمخططات إلى منتجات تعليمية جاهزة للاستخدام، وقد تمثلت في إعداد البيئة التعليمياة الإلكترونية متمثلة بمجموعتين إحداها على الواتس أب (whatsapp) والأخرى على الفيس بوك (Facebook)، كذلك تسجيل المادة

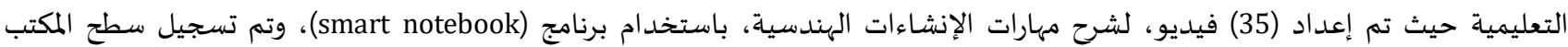
باستخدام (smart recorder)، كذلك استخدام (VSDC Free Video Editor) لمونتاج الفيديو، وإعداد أدوات الدراسة متمثلة بالاختبار المعرفي

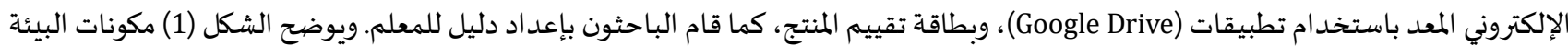
التعليمية الإلكترونية المستخدمة في الدراسة:

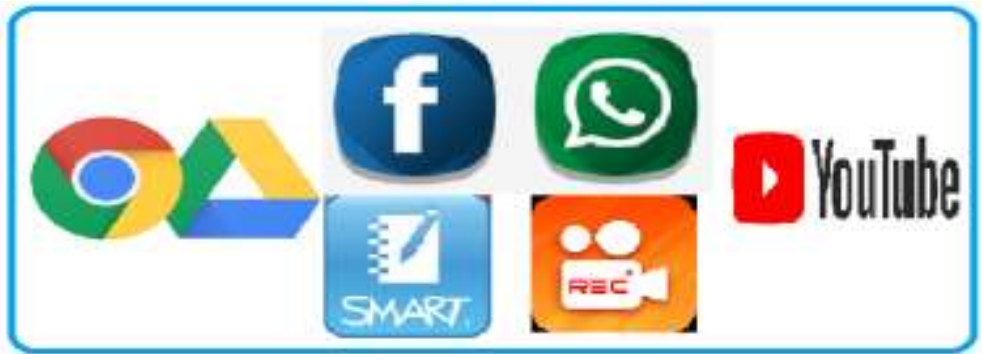

شكل (1): مكونات البيئة التعليمية الإلكترونية المستخدمة في الدراسة

المرحلة الر ابعة: مرحلة التقويم: بعد الانتهاء من تطوير البيئة التعليمية الإلكترونية، قام الباحثون باختبار صلاحيتها والتأكد من سهولة استخدامها

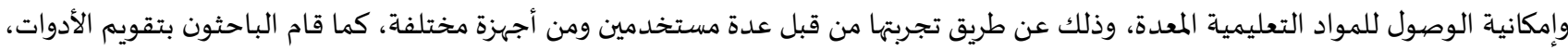

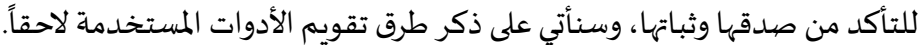
المرحلة الخامسة: مرحلة النشر والاستخدام والمتابعة: وفيها تمّت إضافة الطالبات إلى المجموعات الإلكترونية ومباشرة تنزيل الدروس وشرحها ومتابعتها، وفي النهاية القيام بعملية التقويم باستخدام اختبار إلكتروني. 
المعالجات الإحصائية:

لتحقيق أهداف البحث، استخدمت الباحثون رزمة من المعالجات الإحصائية باستخدام برنامج المعالجة الإحصائي(SPSS-22)، وبرنامج (Microsoft Excel) اختبار(dependent Samples T- Test) للتعرف على الفروق بين مجموعتين مرتبطتين (قبل وبعد التطبيق). اختبار) للتحقق من اعتد الية توزيع البيانات. (Shapiro-Wilk) اختبار ويلك وكسون (Wilcoxon-Test) اللابارمتري وذلك للتعرف على دلالة الفروق بين متوسطي درجات عينتين مرتبطتين بتوزيع غير اعتدالي لنتائج بطاقة التقييم. حساب معامل حجم التأثير (مربع ايتا) و (d) كوهين لحساب الدلالة العملية للبيئة المقترحة، ومعامل الكسب لبلاك.

\section{نتائج الدراسة:}

أولاً : النتائج المتعلقة بالسؤال الأول ومناقشتها:

ينص السؤال الأول من أسئلة البحث على: " ما مهارات الإنشاءات الهـندسية المراد تنميتها لدى طالبات الصهات الصف العاشر؟

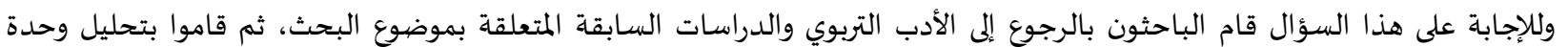
الإنشاءات الهندسية من كتاب الرياضيات المقرر للصف العاشر، لاستخراج المهارات الواردة في هذه الوحدة، ومن ثم تم اعتماد جميع المهارات المقررة، وجدول(7) يوضح قائمة بهذه المهارات.

\begin{tabular}{|c|c|}
\hline 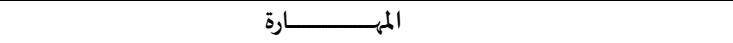 & م \\
\hline مهارة تنصيف قطعة مستقيمة & .1 \\
\hline مهارة تنصيف زاوية & .2 \\
\hline مهارة إنشاء زوايا مختلفة & .3 \\
\hline مهارة نقل الزاوية & .4 \\
\hline مهارة تمثيل حاصل الضرب وناتج القسمة إنشائيا & .5 \\
\hline 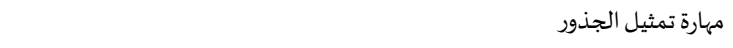 & .6 \\
\hline مهارة إنشاء المثلثات متساوية الساقين ومتساوية الأضلاع & .7 \\
\hline مهارة إنشاء المضلعات المنتظمة & .8 \\
\hline
\end{tabular}

ثانياً : النتائج المتعلقة بالسؤال الثاني ومناقشتها:

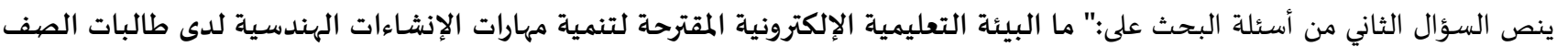
"العاشر؟ للإجابة عن هذا السؤال قام الباحثون بمراجعة الأدبيات التربوية والدراسـات السابقة المتعلقة بالموضوع، ثم قاموا بتصميم بيئة التعلم الإلكترونية، وقد اتبعوا نموذج (خميس، 2003، 417) في تنفيذ خطوات التصميم، ويتكون النموذج من خمس مراحل رئيسة وهي: المرحلة الأولى : مرحلة التحليل: حيث قام الباحثون بإجراء عملية التحليل للمشكلة والأهداف العامة وكذلك تحديد طبيعة المشكلة ومن ثم اقتراح الحلول التعليمية الممكنة والمناسبة للمشكلات، كما تم تحديد خصائص المتعلمين وسلوكهم، وتحليل الموارد في البيئة التعليمية. المرحلة الثانية: مرحلة التصميم: حيث قام الباحثون باتباع خطوات النموذج في مرحلة التصميم، وتمثلت في تصميم الأهداف السلوكية، أدوات القياس، استراتيجية تنظيم المحتوى، وتحديد طرق واستراتيجيات التعليم، كذلك تصميم سيناريو التفاعلات التعليمية واختيار مصادر التعلم. المرحلة الثالثة: مرحلة التطوير: في هذه المرحلة تم تحويل التصميمات والمخططات إلى منتجات تعليمية جاهزة للاستخدام، تمثلت في إعداد البيئة التعليمية الإلكترونية، كذلك تسجيل المادة التعليمية، ومن ثم تسجيل سطح المكتب باستخدام (smart recorder)، كذلك استخدام (VSDC Free Video Editor) لمونتاج الفيديو، وإعداد أدوات الدراسة متمثلة بالاختبار المعرفي الإلكتروني المعد باستخدام تطبيقات (Google Drive)، وبطاقة تقييم المنتج، كما قام الباحثون بإعداد دليل للمعلم. 
المرحلة الر ابعة: مرحلة التقويم:

قام الباحثون باختبار صلاحيتها والتأكد من سهولة استخدامها وإمكانية الوصول للمواد التعليمية المعدة، كما قام الباحثون بتقويم الأدوات،

لمأكد من صدقها وثباتها.

المرحلة الخامسة: مرحلة النشروالاستخدام والمتابعة:

حيث تمّت إضافة الطالبات إلى المجموعات الإلكترونية ومباشرة تنزيل الدروس وشرحها ومتابعتها، واجراء عملية التقويم النهائية.

ثالثاً: النتائج المتعلقة بالسؤال الثالث ومناقشتها:

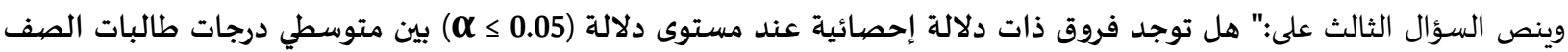

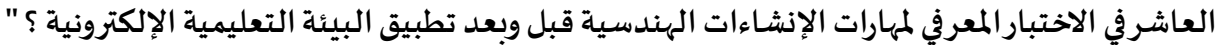

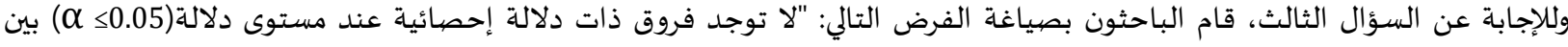

متوسطي درجات طالبات الصف العاشر في الاختبار المعرفي لمهارات الإنشاءات الهندسية قبل وبعد التطبيق، تعزى للبيئة التعليمية الإلكترونية ".

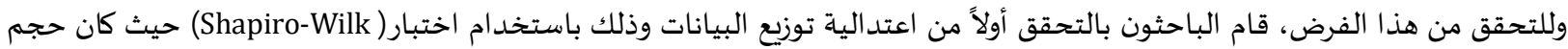

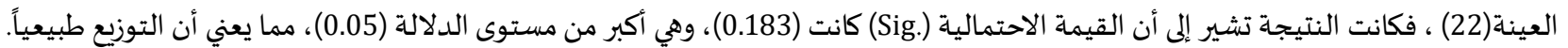

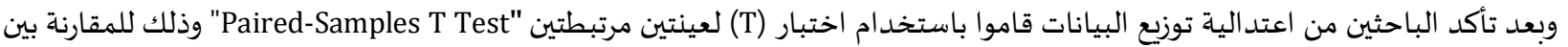

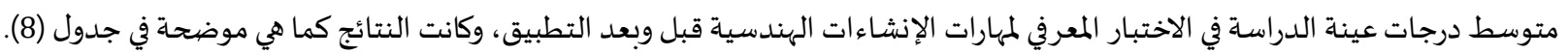

جدول (8): نتائج اختبار (T) لدلالة الفروق بين متوسطات درجات الطالبات في التطبيقين القبلي والبعدي للاختبار المعرفي لمهارات الإنشاءات الهندسية

\begin{tabular}{|c|c|c|c|c|c|c|c|}
\hline \multirow{2}{*}{ مستوى الدلالة } & \multirow{2}{*}{ قالدلالة } & \multirow{2}{*}{ قيمة (T) } & \multicolumn{2}{|c|}{ التطبيق البعدي } & \multicolumn{2}{|c|}{ التطبيق القبلي } & \multirow{2}{*}{ المجال } \\
\hline & & & انحراف معياري & متوسط حسابي & انحراف معياري & متوسط حسابي & \\
\hline دالة إحصائياً & 0.000 & 9.551 & 0.893 & 7.318 & 1.469 & 3.590 & المجال الأول: المعرفة \\
\hline دالة إحصائياً & 0.000 & 46.877 & 1.430 & 15.045 & 0.990 & 3.136 & المجال الثاني: التطبيق \\
\hline دالة إحصائياً & 0.007 & 2.961 & 0.906 & 4.181 & 1.292 & 3.363 & المجال الثالث: \\
\hline دالة إحصبائياً & 0.000 & 24.322 & 2.577 & 26.55 & 2.524 & 10.090 & المجموع الكلي \\
\hline
\end{tabular}

يتبين من جدول (8) وجود فروق ذات دلالة إحصائية بين متوسطي درجات الطالبات في الاختبار المعرفي لمهارات الإنشاءات الهندسية لصالح التطبيق البعدي للاختبار، تعزى للبيئة التعليمية الإلكترونية.

وبذلك نرفض الفرض الصفري ونقبل الفرض البديل، أي أنه "توجد فروق ذات دلالة إحصائية عند مستوى دلالة (0.05 م) بين متوسيطي

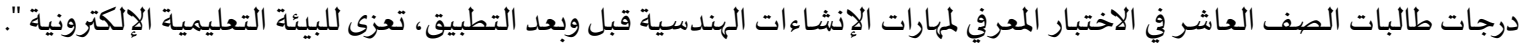

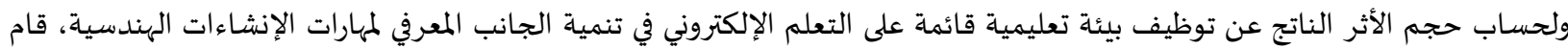

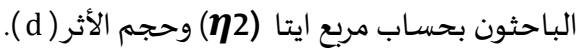

ويوضح جدول (9) حجم تأثير البيئة التعليمية الإلكترونية على تنمية كل مجال من مجالات الاختبار المعرفي لمهارات الإنشاءات الهندسية.

جدول (9): يوضح قيمة مربع إيتا (光 ) وحجم الأثر(d) لمجالات الاختبار المعرفي

\begin{tabular}{|c|c|c|c|c|}
\hline حجم الأثر & D & $\eta 2$ & $\mathrm{~T}$ & المجال \\
\hline كبير & 4.167 & 0.812 & 9.551 & المعرفة \\
\hline كبير & 20.421 & 0.990 & 46.877 & التطبيق \\
\hline كبير & 1.292 & 0.294 & 2.961 & الاستدلال \\
\hline كبير & 10.612 & 0.965 & 24.322 & المجموع الكلي \\
\hline
\end{tabular}

ويتضح من الجدول (9) أن قيم كل من مربع ايتا "Y2" وحجم الاثر "d" كبير لكل من مستوى المعرفة والتطبيق والمجموع الكلي للاختبار، وكبير

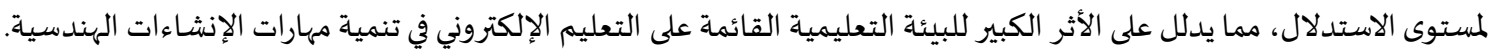

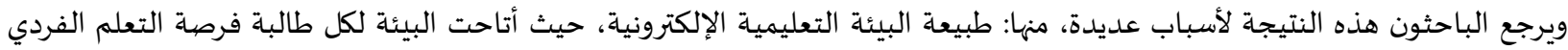

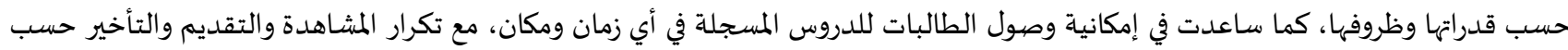

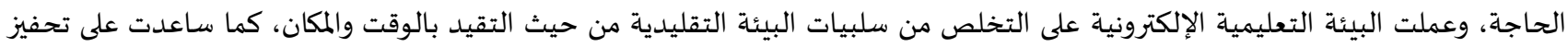


جميع الطالبات للمشاركة والنقاش دون خجل أو خوف، كذلك التفاعل مع بعضهن البعض. وزاد استخدام البيئة التعليمية الإلكترونية والمواد

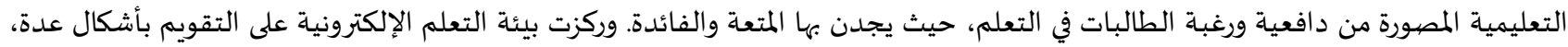

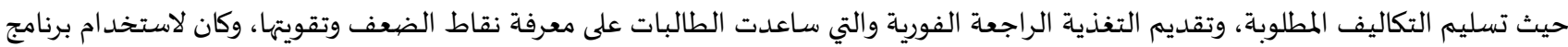
الأثر البالغ في جذب الطالبات لمتابعة الدروس، حيث المؤثرات البصرية والسمعية. ساعد قيام الباحثون بتقويم الطالبات (Smart Notebook) واختبارهن إلكترونياً، في تخفيف التوتر الناجم عن جو الاختبارات، كما أتاح لهن فرصة اختيار الوقت المناسب للتقدم للاختبار في إطار الزمن المتاح. وساعد استخدام الباحثون لنموذج خميس في إعد اد بيئة التعلم الإلكترونية المناسباة.

وتتفق نتائج الدراسـة مع عدة دراسـات تهدف إلى الكشف عن فاعلية بيئة تعليمية إلكترونية في تنمية الجوانب المهارية مثل : دراسة شامية (2018

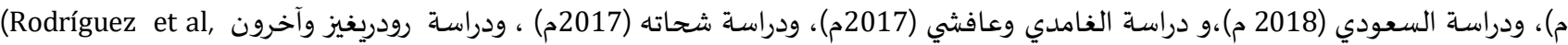

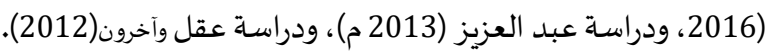

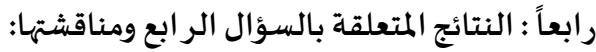

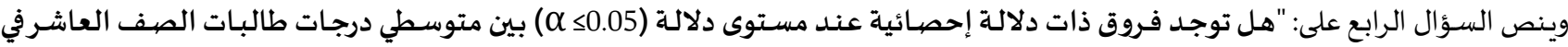

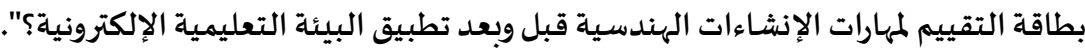
وللتحقق من هذا الفرض، قام الباحثون بالتحقق أولاً من اعتدالية توزيع البيانات وذلك باستخدام اختبار(Shapiro-Wilk) حيث أن حجم

العينة(22)

وبناءً على نتائج اختبار (Shapiro-Wilk) تبين للباحثين أن توزيع نتائج بطاقة التقييم يتبع التوزبع الغير الطبيعي، لذلك استخدم الباحثون اختبار ويلك وكسون "Test - Wilcoxon" اللابارمتري وذلك للتعرف على دلالة الفروق بين متوسطي درجات عينتين مرتبطتين ( الأداء القبلي والبعدي ) في بطاقة تقييم الجانب الأدائي لمهارات الإنشاءات الهندسية. والجدول(10) يوضح ذلك: جدول (10): نتائج اختبار"Test" لدلالة الفروق بين متوسطات درجات الطالبات في التطبيقين القبلي والبعدي لبطاقة تقييم مهارات الإنشاءات

\begin{tabular}{|c|c|c|c|c|c|c|c|}
\hline \multicolumn{8}{|c|}{ الهندسية } \\
\hline مستوى الدلالة & قيمة الدلالة & قيمة "Z" ق " & مجموع الرتب & متوسط الرتب & 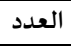 & البيان & المجال \\
\hline \multirow[t]{4}{*}{0.01} & 0.000 & $\begin{array}{l}-4.070-\mathrm{b} \\
\end{array}$ & 00 & 00 & 00 & الرتبة السالبة & \\
\hline & & & 231 & 11 & 21 & الرتبة الموجبة & توظيف استخدام الفرجار \\
\hline & & & & & 1 & التساوي & \\
\hline & & & & & 22 & المجموع & \\
\hline \multirow[t]{4}{*}{0.01} & 0.000 & $-4.091-\mathrm{b}$ & 00 & 00 & 00 & الرتبة السالبة & توظيف استخدام الحافة \\
\hline & & & 231 & 11 & 21 & الرتبة الموجبة & المستقيمة \\
\hline & & & & & 1 & التساوي & \\
\hline & & & & & 22 & المجموع & \\
\hline \multirow[t]{4}{*}{0.01} & 0.000 & $-4.020-\mathrm{b}$ & 1 & 1 & 1 & الرتبة السـالبة & \\
\hline & & & 230 & 11.5 & 20 & الرتبة الموجبة & تنفيذ الخطوات \\
\hline & & & & & 1 & التساوي & \\
\hline & & & & & 22 & المجموع & \\
\hline \multirow[t]{4}{*}{0.01} & 0.000 & $-4.041-\mathrm{b}$ & 00 & 00 & 00 & الرتبة السالبة & \\
\hline & & & 231 & 11 & 21 & الرتبة الموجبة & الإخراج الهائي \\
\hline & & & & & 1 & التساوي & \\
\hline & & & & & 22 & المجموع & \\
\hline \multirow[t]{4}{*}{0.01} & 0.000 & $-4.117-\mathrm{b}$ & 00 & 00 & 00 & الرتبة السـالبة & \\
\hline & & & 253 & 11.5 & 22 & الرتبة الموجبة & المجموع \\
\hline & & & & & 00 & التساوي & \\
\hline & & & & & 22 & المجموع & \\
\hline
\end{tabular}

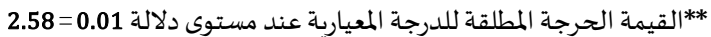
*القيمة الحرجة المطلقة للدرجة المعيارية عند مستوى دلالة 0.05 = 1.96

يتضح من جدول (10) وجود فروق ذات دلالة إحصائية بين متوسطي درجات الطالبات في بطاقة التقييم لمهارات الإنشاءات الهندسية قبل وبعد التطبيق لصالح التطبيق البعدي لبطاقة التقييم. وبذلك نرفض الفرض الصفري ونقبل الفرض البديل، أي انه توجد فروق ذات دلالة إحصائية عند مستوى دلالة (0.05 $)$ بين متوسطي درجات طالبات الصف العاشر في بطاقة التقييم لمهارات الإنشاءات الهندسية قبل وبعد التطبيق. 
حجم تأثير البيئة التعليمية الإلكترونية على الأداء العملي:

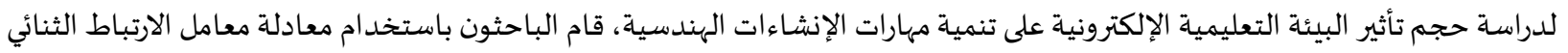
لرتب الأزواج المرتبطة"Rprb" ومعادلة "dcohen" وذلك لحساب حجم التأثير عند استخد ام "ويلكوكسون" للعينتين المرتبطتين. يوضح جدول (11) حساب حجم الأثر"Rprb " لكل مجال من مجالات بطاقة التقييم :

\begin{tabular}{|c|c|c|c|}
\hline حجم الأثر & $R p r b$ & $T$ & المجال \\
\hline كبير & 0.826087 & 231 & توظيف استخدام الفرجار \\
\hline 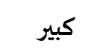 & 0.826087 & 231 & توظيف استخدام الحافة المستقيمة \\
\hline 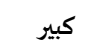 & 0.818182 & 230 & تنفيذ الخطوات \\
\hline 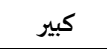 & 0.826087 & 231 & الإخراج النهائي \\
\hline كبيرجداً & 1 & 253 & المجموع \\
\hline
\end{tabular}

يتضح من جدول (11) أن حجم التأثير لجميع مجالات بطاقة التقييم كانت كبيرة، بينما كانت كبيرة جداً للمجموع النهائي، مما يدلل على فاعلية

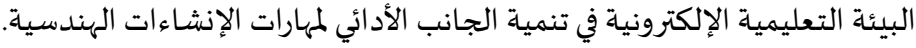

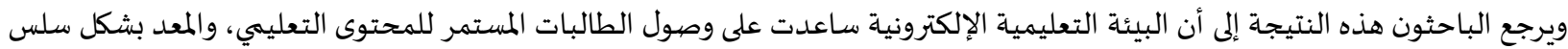
وجذاب، كما أتاحت البيئة التعليمية الإلكترونية للطالبات التدقيق في آلية استخدام الفرجار والحافة المستقيماة، ومتابعة تسلسل الخطوات وتبريرها

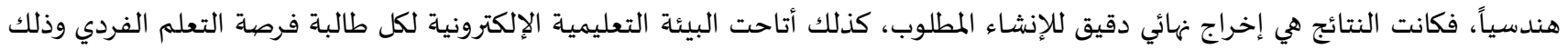
حسب قدراتها الذاتية، وعززت من ميول الطالبات نحو التعلم، وجعلتهن أكثر تفاعلاً، كما منحت الطالبات فرصة الممارسة العملية لجميع المهارات والتواصل المستمر للمناقشة والحوار وإعطاء التغذية الراجعة. اتِفقت الدراسة الحالية مع دراسة كل من شامية (2018 م)، ودراسة عقل وآخرون( 2012 م)، ودراسة السعودي (2018 م)، ودراسة الغامدي

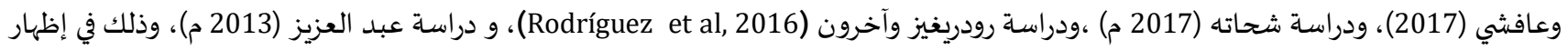
فاعلية البيئة التعليمية الإلكترونية في تنمية جوانب مهارية مختلفة، واختلفت معها في نوع المهارة وهي مهارات الإنشاءات الهندسية في هذه الدراسـة.

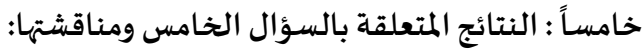

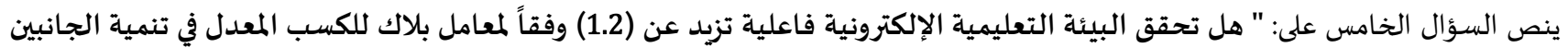

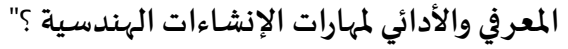

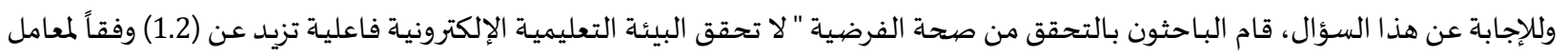
بلاك للكسب المعدل في تنمية الجانبين المعرفي والأدائي لمهارات الإنشاءات الهندسية ". وذلك باستخدام معادلة معامل بلاك للكسب المعدل لحساب الفاعلية: معادلة معامل بلاك للكسب المعدل = المتوسط البعدي - المتوسط القبلي + المتوسط البعدي - المتوسط القبلي

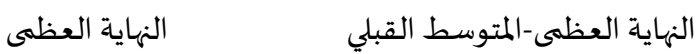

ويوضح الجدول (12) معامل الكسب بلاك للاختبار المعرفي.

جدول (12): معامل بلاك للكسب المعدل للاختبار المعرفي

\begin{tabular}{|c|c|c|c|c|}
\hline معامل بلاك & النهاية العظهى & المتوسط البعدي & المتوسط القبلي & المجال \\
\hline 1.311 & 8 & 7.318 & 3.590 & المعرفة \\
\hline 1.559 & 17 & 15.045 & 3.136 & التطبيق \\
\hline 0.663 & 5 & 4.181 & 3.363 & الاستدلال \\
\hline 1.375 & 30 & 26.55 & 10.090 & المجموع الكلي \\
\hline
\end{tabular}

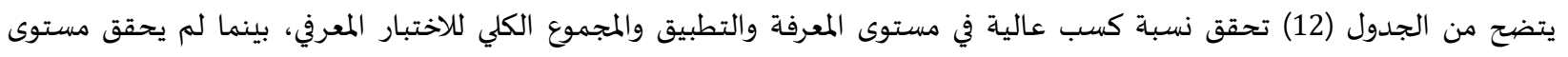
الاستدلال النسبة المطلوبة حيث بلغ (0.663)؛ إذ أن نسبة الأهداف في المنهاج بمستوى الاستدلال قليلة جداً، حيث التركيز على مستويات المعرفة

والتطبيق، لذلك يرى الباحثون ضرورة التركيز على تنمية هذا الجانب مستقبلاً.

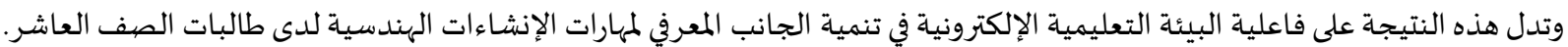
يوضح الجدول (13) معامل بلاك للكسب المعدل لبطاقة التقييم: 


\begin{tabular}{|c|c|c|c|c|}
\hline معامل بلاك & النهاية العظمى & المتوسط البعدي & المتوسط القبلي & 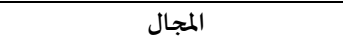 \\
\hline 1.356 & 12 & 10.954 & 4.909 & توظيف استخدام الفرجار \\
\hline 1.334 & 6 & 5.363 & 2.318 & توظيف استخدام الحافة المستقيمة \\
\hline 1.304 & 9 & 7.909 & 3.409 & تنفيذ الخطوات \\
\hline 1.162 & 9 & 7.590 & 3.727 & الإخراج النهائي \\
\hline 1.291 & 36 & 31.363 & 14.590 & المجموع \\
\hline
\end{tabular}

يتضح من الجدول (13) تحقق نسبة الكسب المعدل المطلوبة لكل من استخدام الفرجار واستخدام الحافة المستقيمة وتنفيذ الخطوات، كذلك المبات

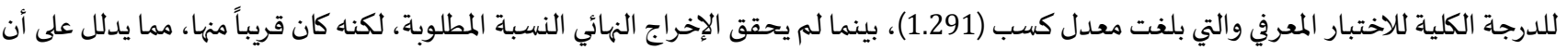

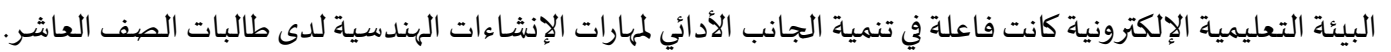
وبذلك نرفض الفرض الصفري ونقبل الفرض البديل، والذي ينص على أنه " تحقق البيئة التعليمية الإلكترونية فاعلية تزبد عن (1.2) وفقاً

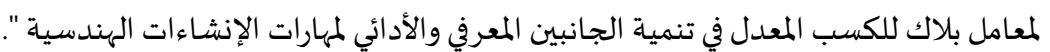
وبذلك يكون الباحثون قد أجابوا عن جميع أسئلة الدراسة، وتحققوا من صحة فرضياتها، وتوصلوا إلى فاعلياتياتية البيائة التعليمية الإلكترونية في تنمية مهارات الإنشاءات الهندسية بجانبيها المعرفي والأدائي. وتتفق نتائج هذه الدراسة مع كل من دراسة شامية (2018) ودراسة السعودي (2018) وداسلة ودراسية (2018) ودراسة الغامدي وعافشي (2017) ودراسة شحاتة

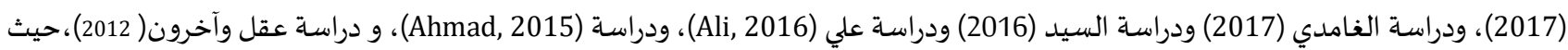
أكدت جميع هذه الدراسات فاعلية البيئة التعليمية الإلكترونية في تنمية الأداء المهاري. التوصيات:

في ضوء ما توصل إليه الباحثون من نتائج، فإنهم يوصون بما يلي:

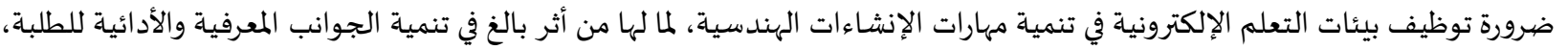

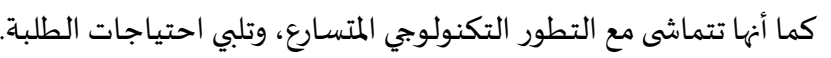
أظهرت النتائج أن الاستدلال لم يحقق مستوى كسب كبير، لذلك يوصي الباحثون بابتكار وسائل تساعد على تنمية التفكير الاستدلالي لدى الطلبة. نتيجة لعدم تمكن الباحثون من استخدام المنهج التجريبي ذو المجموعتين نتيجة لوجود أزمة Covid19، يوصى الباحثين بتطبيق الدراسة باستخدام هذا المنهج.

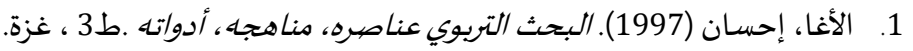
2. 3. أديب، عادل نسيم (2009). الهندسة التحليلية. دار المنهل.

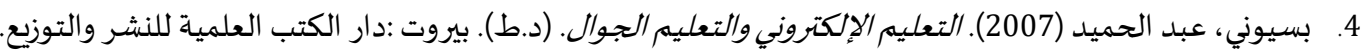

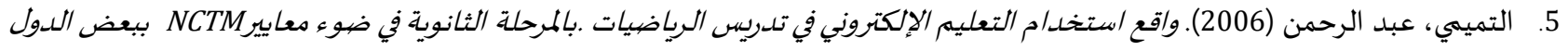

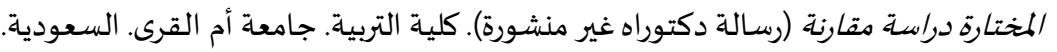

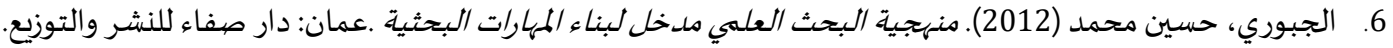

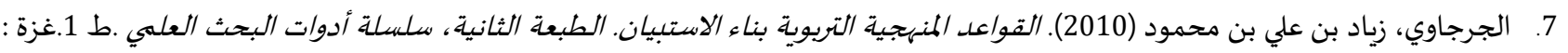
مطبعة أبناء الجراح. 8. أبو حطب، فؤاد، وصادق، آمال (1980). علم النفس التبريوي. ط2 ـ مكتبة الأنجلو المصرية: القاهرة.

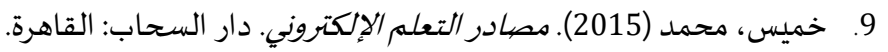

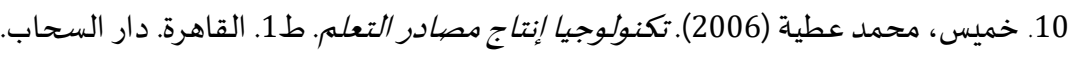
11. الدمرداش، محمد والحنفي، أمل (2019). الإنشاءات الهندسية (تداجية (تدريبات عملية). مصر. 
12. الدمرداش، محمد السيد أحمد، وأمل محمد مختار الحنفي (2018). استخدام الإنشاءات الهندسية في تنمية بعض جوانب التعلم الهندسية والرياضية ومستويات التفكير الهندسي لدى الطلاب المعلمين شعبة الرياضيات. مجلة تربويات الرياضيات: الجمعية المصرية لتربويات الرياضيات

125 - 70 : 10$) 21$

13. الراشد، فارس بن إبراهيم (1424هـ). التعليم الإككتروني واقع وطموح. ورقة عمل مقدمة لندوة التعليم الإلكتروني. مدارس الملك فيصل. الرياض.

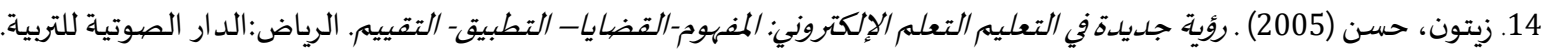
15. السيد، مصطفى.(2016). فاعلية تصميم بيئة تعلم إلكتروني تشاركي في تنمية مفاهيم محركات بحث الويب غير المرئية ومعتقدات الكفاءة الذاتية للدى طلاب كلية التوبية. العدد - 122 مجلة القراءة والمعرفة - مصيدر.

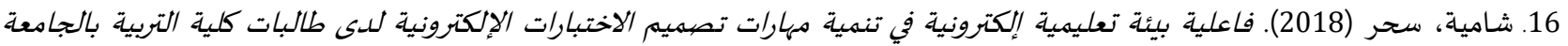
الإسالامية بغنة. رسالة ماجستير غير منشورة.الجامعة الإسلامية. غزة. فلسطين. 17. شحاته، نشوى (2017). تصهميم بيئة تعلم إلكترونية في ضيوء النظرية التواصلية وأثثها في تنمية مهارات التفكير الناقد لدى لدى طلاب كلية التربية. تكنولوجيا التربية-دراسات وبحوث- مصر. 18. أبو شحادة، كفاية (2016). فاعلية بنامج مقترح في العلوم قائم على التعلم المددمج في تنمية المفاهيم العلمية والتفكير الاستقصبائي وال تجاه نحور المادة لدى تلاميذ المسحلة الأساسية العليا في فلسطين. رسالة دكتوراه. معهد الدراسات التربوية. جامعة القاهرة.

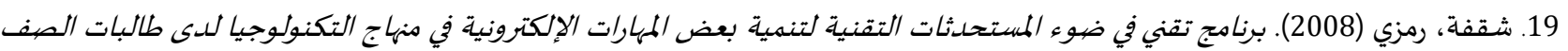
العاشر الأساسي.( رسالة ماجستير غير منشورة). الجامعة الإسلامية، غزة.

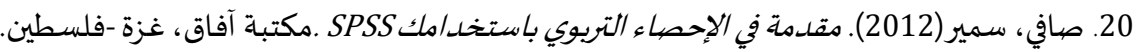
21. طعيمة، رشدي(2004). تحليل المحتوى في العلوم الإنسانية.( د.ط). القاهرة: دار الفكر العربي.

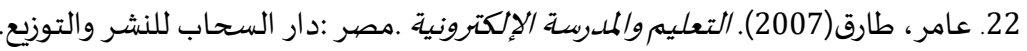

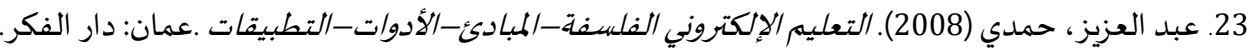

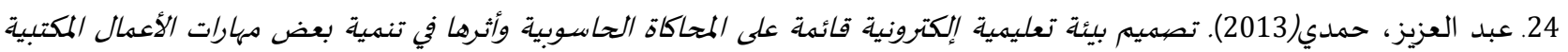
وتحسين مهارات التعلم لدى طلاب المدارس الثانوية التحجارية .المجلة الأردنية في العلوم التربوية.

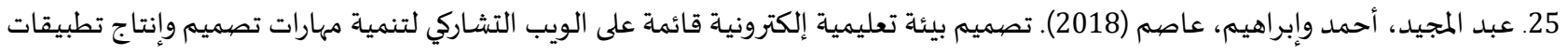

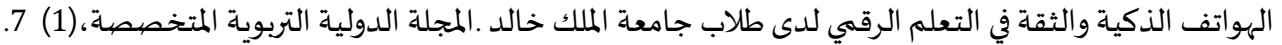
26. عبيد، وليم والمفتي، محمد ونوح،محمد (1988). طرق تلدريس الرياضيات. المقرر الثاني،المستوى الرابع وبرنامج تأهيل معلهي المرحلة الابتدائية

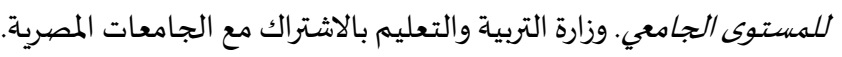

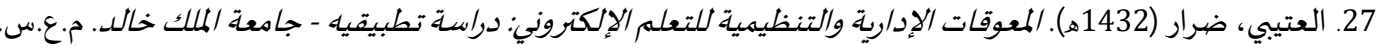

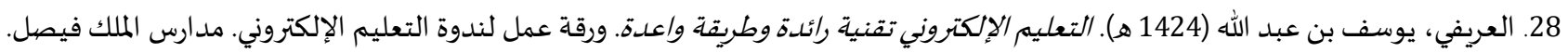
الرياض.

29. عفانة، عزو ونشوان، تيسير (2017) . اتجاهات حلديثة في القياس والتقويم التويوي. غزة: سمير منصور للنشر والتوزيع. 30. العفون، نادية (2012). الاتجاهات الحسديثة في التفكير وتنمية التفكير .ط1 ، عمان :دار الصفاء.

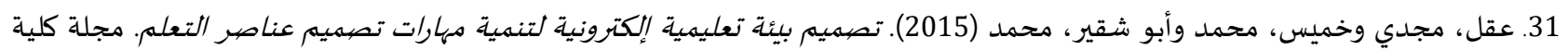

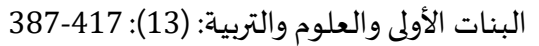
32. أبو عميرة، محبات (1993). تجبريب استخدام بعض طرائق مقترحة في التغلب على صعوبات تعلم الهندسة الفراغية لدى طانى طلاب الصفف الثاني

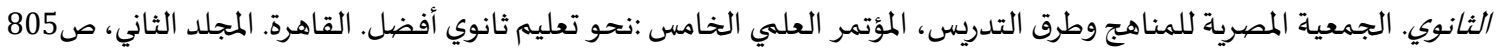

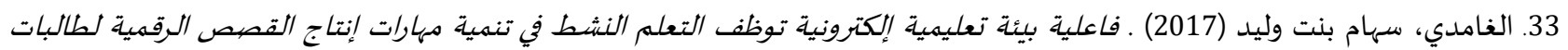
جامعة الأميرة نورا. مجلة العلوم التربوية. 34. الغامدي، منى وابتسام، عافشي (2018). فاعلية بئة تعليمية إلكترونية قائمة على التعلم التشاركي في تنمية التفكير الناقد لدى لدى طالبات كلية

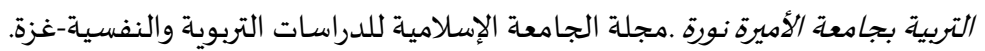

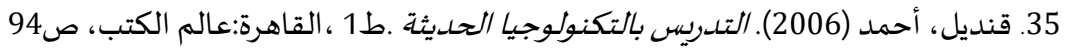

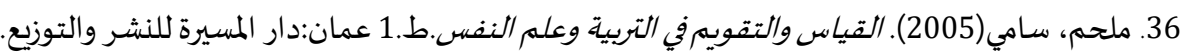


37. موسى، محمد فؤاد.(1989 ). أثر استخدام بعض الإستراتيجيات في تدريس الإنشاءات الهندسية بالصف الأول الإعدادي على مهارة إجرائها. مجلة

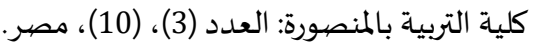

38. نوح، محمد مسعد (1992). دراسة العلاقة بين تحصيل كتابة البراهين في الهندسة والإنشاء/ت الهندسية ومفهوم التلامين عن طبيعة البرهان الهندسي. جامعاة عين شمس-كلية التربية. مصر. ثانياً: المراجع الأجنبية:

1. Ahmed. S. (2015). The Effect of Using Electronic Learning Contracts on EFL Students Self-directed Learning Readiness. Al Manofia university. Egypt.

2. Ali، A. (2016). Learning Gains of E-learning Environments as Perceived by Qatari Middle \& High School Students. Qatar University. Qatar.

3. Chou، S. W. \& \& Liu، C. H. (2005). Learning effectiveness in a Web-based virtual learning environment: a learner control perspective. Journal of computer assisted learning، 21(1): 65-76, https://doi.org/10.1111/j.1365-2729.2005.00114.x.

4. Henderson، A. (2002). The E-Learning Question and Answer Book: A Survival Guide for Trainers and Business Managers.

5. Horton، W.، \& Horton، K. (2003). E-learning Tools and Technologies: A consumer's guide for trainers، teachers، educators، and instructional designers. John Wiley \& Sons

6. Karpuz.W. \& Atasoy، E. (2018). Investigation of 9th Grade Students' Geometrical Figure Apprehension. Recep Tayyip Erdogan University، TURKEY.

7. Lim-Teo، S. K. (1997). Compass constructions: a vehicle for promoting relational understanding and higher order thinking skills. The Mathematics Educator, 2(2): 138-147.

8. Rodríguez، G.; Quesada-Serra، V. \& Ibarra-Sáiz، S. (2016). Learning-oriented E Assessment: The effects of a training and guidance program on lecturers' perceptions. Assessment \& Evaluation in Higher Education, 41 (1):35-52, https://doi.org/10.1080/02602938.2014.979132.

9. Yavuz Karpuz \& TURKEY Ercan Atasoy. (2018). Investigation of 9th Grade Students' Geometrical Figure Apprehension. Recep Tayyip Erdogan University، TURKEY 


\title{
The effectiveness of e-learning environment in developing geometric constructions skills in mathematics, among $10^{\text {th }}$ graders
}

\author{
1Mohammed F. Abu owda, ${ }^{2}$ Magdy S. Aqel, ${ }^{3}$ Khadeja M. Bedwan
}

${ }^{1}$ Assist Professor of Curriculum and Science Teaching, Faculty of Education, Islamic University of Gaza, Palestine

${ }^{2}$ Associate Professor of Curriculum and Instructional Technology, Islamic University of Gaza, Palestine ${ }^{3}$ Curriculum and Teaching Methods Researcher, Faculty of Education - Islamic University of Gaza, Palestine

1 modaa@iugaza.edu.ps, ${ }^{2}$ msaqel@iugaza.edu.ps, ${ }^{3}$ Eng.khbedwan1@gmail.com

Received : 7/11/2020 Revised : 28/11/2020 Accepted : 1/1/2021 DOI : https://doi.org/10.31559/EPS2021.9.3.5

Abstract: The research aimed to reveal the effectiveness of E-learning environment in developing geometric construction skills in mathematics among $10^{\text {th }}$ graders in Palestine. and the research followed the quasiexperimental curriculum by designing one experimental group (Pre- post). And the researchers built the study tools represented in a cognitive test and an assessment card to measure geometric construction skills, which were applied to a sample of (22) $10^{\text {th }}$ grade female students from Ali bin Abi Talib Secondary School for Girls. The research concluded the effectiveness of the electronic educational environment in developing geometric construction skills, as the black gain rate was (1.37), as well as the existence of statistically significant differences at the level of significance $(\alpha=0.05)$ between the average scores of the $10^{\text {th }}$ grade students in the cognitive test of geometric construction skills before \& after the application in favor of the post application, there were also statistically significant differences at the level of significance $(\alpha=0.05)$ between the mean scores of the tenth grade students in the assessment card for geometric construction skills before and after the application in favor of the post application. The research recommended employing electronic learning environments in teaching geometric constructions، and working on holding training courses in e-learning for teachers.

Keywords: E-learning environment; geometric construction skills.

\section{References:}

1. 'amr, Tarq(2007). Alt'lym Walmdrsh Alelktrwnyh. Msr: Dar Alshab Llnshr Waltwzy'.

2. 'bd Al'zyz, Hmdy (2008). Alt'lym Alelktrwny Alflsfh-Almbad'-Aladwat-Alttbyqat. 'man: Dar Alfkr.

3. 'bd Al'zyz, Hmdy(2013). Tsmym By'h T'lymyh Elktrwnyh Qa'mh 'la Almhakah Alhaswbyh Wathrha Fy Tnmyt B'd Mharat Ala'mal Almktbyh Wthsyn Mharat Alt'Im Lda Tlab Almdars Althanwyh Altjaryh. Almjlh Alardnyh Fy Al'lwm Altrbwyh.

4. 'bd Almjyd, Ahmd Webrahym, 'asm (2018). Tsmym By'h T'lymyh Elktrwnyh Qa'mh 'la Alwyb Altsharky Ltnmyt Mharat Tsmym Wentaj Ttbyqat Alhwatf Aldkyh Walthqh Fy Alt'lm Alrqmy Lda Tlab Jam't Almlk Khald. Almjlh Aldwlyh Altrbwyh Almtkhssh,7 (1).

5. 'byd, Wlym Walmfty, Mhmd Wnwh, Mhmd (1988). Trq Tdrys Alryadyat. Almqrr Althany, Almstwa Alrab' Wbrnamj Tahyl M'Imy Almrhlh Alabtda'yh Llmstwa Aljam'y. Wzarh Altrbyh Walt'elym Balashtrak M' Aljam'at Almsryh.

6. Al'tyby, Drar (1432h). Alm'wqat Aledaryh Waltnzymyh Llt'lm Alelktrwny: Drash Ttbyqyh - Jam't Almlk Khald. M.'.S.

7. Al'ryfy, Ywsf Bn 'bd Allh (1424 H). Alt'lym Alelktrwny Tqnyh Ra'dh Wtryqh Wa'edh. Wrqh 'ml Lndwh Alt'lym Alelktrwny. Mdars Almlk Fysl. Alryad.

8. ' 'fanh, 'zw Wnshwan, Tysyr (2017). Atjahat Hdythh Fy Alqyas Waltqwym Altrbwy. Ghzh: Smyr Mnswr Llnshr Waltwzy'.

9. Al'fwn, Nadyh (2012). Alatjahat Alhdythh Fy Altfkyr Wtnmyt Altfkyr. T 1, 'man: Dar Alsfa'. 
10. 'ql, Mjdy Wkhmys, Mhmd Wabw Shqyr, Mhmd (2015). Tsmym By'h T'lymyh Elktrwnyh Ltnmyt Mharat Tsmym 'nasr Alt'lm. Mjlt Klyt Albnat Alawla Wal'lwm Waltrbyh: (13): 387-417

11. Abw 'myrh, Mhbat (1993). Tjryb Astkhdam B'd Tra'q Mqtrhh Fy Altghlb 'la S'wbat T'lm Alhndsh Alfraghyh Lda Tlab Alsf Althany Althanwy. Aljm'yh Almsryh Llmnahj Wtrq Altdrys, Alm'tmr Al'Imy Alkhams: Nhw T'lym Thanwy Afdl. Alqahrh. Almjld Althany, S 805.

12. Alagha, Ehsan (1997). Albhth Altrbwy 'nasrh, Mnahjh, Adwath. T 3, Ghzh.

13. Alagha, Ehsan Walastad, Mhmwd (2007). Mqdmh Fy Tsmym Albhth Altrbwy.T 5, Ghzh: Mktbt Altalb, Aljam'h Aleslamyh.

14. Adyb, 'adl Nsym (2009). Alhndsh Althlylyh. Dar Almnhl.

15. Bsywny, 'bd Alhmyd (2007). Alt'lym Alelktrwny Walt'lym Aljwal. (D.T). Byrwt: Dar Alktb Al'lmyh Llnshr Waltwzy'.

16. Aldmrdash, Mhmd Walhnfy, Aml (2019). Alensha'at Alhndsyh (Tdrybat 'mlyh). Msr.

17. Aldmrdash, Mhmd Alsyd Ahmd, Waml Mhmd Mkhtar Alhnfy (2018). Astkhdam Alensha'at Alhndsyh Fy Tnmyt B'd Jwanb Alt'lm Alhndsyh Walryadyh Wmstwyat Altfkyr Alhndsy Lda Altlab Alm'lmyn Shebh Alryadyat. Mjlt Trbwyat Alryadyat: Aljm'yh Almsryh Ltrbwyat Alryadyat 21(10): 70 - 125.

18. Alghamdy, Sham Bnt Wlyd (2017). Fa'lyt By'h T'lymyh Elktrwnyh Twzf Alt'lm Alnsht Fy Tnmyh Mharat Entaj Alqss Alrqmyh Ltalbat Jam't Alamyrh Nwra. Mjlt Al'lwm Altrbwyh.

19. Alghamdy, Mna Wabtsam, 'afshy (2018). Fa'lyt By'h T'lymyh Elktrwnyh Qa'mh 'la Alt'lm Altsharky Fy Tnmyt Altfkyr Alnaqd Lda Talbat Klyh Altrbyh Bjam't Alamyrh Nwrh. Mjlt Aljam'h Aleslamyh Lldrasat Altrbwyh Walnfsyh-Ghzh.

20. Abw Htb, F'ad, Wsadq, Amal (1980). 'Im Alnfs Altrbwy. T 2. Mktbh Alanjlw Almsryh: Alqahrh.

21. Aljbwry, Hsyn Mhmd (2012). Mnhjyt Albhth Al'lmy Mdkhl Lbna' Almharat Albhthyh. 'man: Dar Sfa' Llnshr Waltwzy'.

22. Aljrjawy, Zyad Bn 'ly Bn Mhmwd (2010). Alqwa'd Almnhjyh Altrbwyh Bna' Alastbyan. Altb'h Althanyh, Slslt Adwat Albhth Al'lmy. T.1 Ghzh: Mtb't Abna' Aljrah.

23. Khmys, Mhmd (2015). Msadr Alt'lm Alelktrwny. Dar Alshab: Alqahrh.

24. Khmys, Mhmd 'tyh (2006). Tknwlwjya Entaj Msadr Alt'lm. T1. Alqahrh. Dar Alshab.

25. Mlhm, Samy (2005). Alqyas Waltqwym Fy Altrbyh W'Im Alnfs.T 1.'man: Dar Almsyrh Llnshr Waltwzy'.

26. Mwsa, Mhmd F'ad. (1989). Athr Astkhdam B'd Alestratyjyat Fy Tdrys Alensha'at Alhndsyh Balsf Alawl Ale'dady 'la Mharh Ejra'ha. Mjlt Klyh Altrbyh Balmnswrh: Al'dd (3), (10), Msr.

27. Nwh, Mhmd Ms'ed (1992). Drash Al'laqh Byn Thsyl Ktabt Albrahyn Fy Alhndsh Walensha'at Alhndsyh Wmfhwm Altlamyd 'n Tby't Albrhan Alhndsy. Jam't 'yn Shms ᄀᄀ-Klyt Altrbyh. Msr.

28. Qndyl, Ahmd (2006). Altdrys Baltknwlwjya Alhdythh. T 1, Alqahrh:'alm Alktb, S. 94

29. Alrashd, Fars Bn Ebrahym1424) H). Alt'lym Alelktrwny Waq' Wtmwh. Wrqh 'Eml Mqdmh Lndwh Alt'lym Alelktrwny. Mdars Almlk Fysl. Alryad.

30. Safy, Smyr2012)). Mqdmh Fy Alehsa' Altrbwy Bastkhdamk. Spss Mktbt Afaq, Ghzh- Flstyn.

31. Shamyh, Shr (2018). Fa'lyt Byeh T'lymyh Elktrwnyh Fy Tnmyt Mharat Tsmym Alakhtbarat Alelktrwnyh Lda Talbat Klyt Altrbyh Baljam'h Aleslamyh Bghzh. Rsalt Majstyr Ghyr Mnshwrh.Aljam'h Aleslamyh. Ghzh. Flstyn.

32. Abw Shhadh, Kfayh (2016). Fa'lyt Brnamj Mqtrh Fy Al'lwm Qa'm 'la Alt'lm Almdmj Fy Tnmyt Almfahym Al'Imyh Waltfkyr Alastqsa'y Wal Tjah Nhw Almadh Lda Tlamyd Almrhlh Alasasyh Al'lya Fy Flstyn. Rsalt Dktwrah. M'hd Aldrasat Altrbwyh. Jam't Alqahrh.

33. Shhath, Nshwa 2017)). Tsmym By'h T'lm Elktrwnyh Fy Dw' Alnzryh Altwaslyh Wathrha Fy Tnmyt Mharat Altfkyr Alnaqd Lda Tlab Klyt Altrbyh. Tknwlwjya Altrbyh-Drasat Wbhwth- Msr.

34. Shqfh, Rmzy (2008). Brnamj Tqny Fy Dw' Almsthdthat Altqnyh Ltnmyh B'd Almharat Alelktrwnyh Fy Mnhaj Altknwlwjya Lda Talbat Alsf Al'ashr Alasasy. ) Rsalt Majstyr Ghyr Mnshwrh). Aljam'h Aleslamyh, Ghzh.

35. Alsyd, Mstfa. (2016). Fa'lyt Tsmym By't T'lm Elktrwny Tsharky Fy Tnmyt Mfahym Mhrkat Bhth Alwyb Ghyr Almr'yh Wm'tqdat Alkfa'h Aldatyh Lda Tlab Klyt Altrbyh. Al'dd 122 - Mjlt Alqra'h Walm'rfh - Msr.

36. T'eymh, Rshdy(2004). Thlyl Almhtwa Fy Al'elwm Alensanyh. (D.T). Alqahrh: Dar Alfkr Al'rby.

37. Altmymy, 'bd Alrhmn(2006). Waq' Astkhdam Alt'lym Alelktrwny Fy Tdrys Alryadyat. Balmrhlh Althanwyh Fy Dw' M'ayyr Nctm Bb'd Aldwl Almkhtarh Drash Mqarnh (Rsalt Dktwrah Ghyr Mnshwrh). Klyt Altrbyh. Jam't Am Alqra. Als'wdyh.

38. Zytwn, Hsn. (2005) R'yh Jdydh Fy Alt'lym Alt'lm Alelktrwny: Almfhwm-Alqdaya -Alttbyq- Altqyym. Alryad: Aldar Alswtyh Lltrbyh. 